$\underline{\xi}=-m$

\title{
Pharmacokinetics of thiamphenicol in normal and pasteurella multocida infected lactating goats
}

\author{
El Komy ,Ashraf Abd El Hakim 1, , El Sayed, Mossad Gamal Eldin Ahmed ${ }^{2}$, Faten Ibrahim El Sayed *2 \\ ${ }^{1}$ Fac. Vet. Med., Pharmacology Dept., Benha University, Egypt, El-Qaliubeya, Toukh, Moshtohor \\ ${ }^{2}$ Department of pharmacology, Faculty of Veterinary Medicine, Benha University, Egypt \\ *Corresponding author E-mail: fatennn86@yahoo.com
}

\begin{abstract}
The pharmacokinetic parameters of thiamphenicol following intravenous and intramuscular (single \& repeated) administrations were estimated in normal and experimentally pasteurella multocida infected goats. Following a single intravenous injection of $30 \mathrm{mg}$ thiamphenicol $/ \mathrm{kg}$ b.wt. in normal goats, thiamphenicol could be detected therapeutically for 24 hours post intravenous injection. The serum concentration - time curve of thiamphenicol following intravenous injection showed that the drug obeyed a two compartments open model. The intramuscular bioavailability of thiamphenicol in normal goats was $66.63 \%$. Intramuscular injection of $30 \mathrm{mg}$ thiamphenicol per kilogram body weight once daily for five consecutive days in normal and pastreulla multocida infected goats revealed a lower significant serum thiamphenicol concentration in pastreulla multocida infected goats compared with normal goats, also it's found that: marked significant decrease in $(\mathrm{k} 1, \mathrm{~K} 12, \mathrm{~K} 21, \mathrm{~T} 0.5(\alpha), \mathrm{T} 0.5(\beta)$, Tmax and CLtot in normal compared with infected goats, on the other hand a significant increase in Cmax,AUC, $\mathrm{C} 0, \mathrm{~B}$ and $\beta$ in normal compared with infected goats. Thiamphenicol was cleared by all clearance processes (Cltot) in the body at significant faster rates in Pasteurella multocida infected goats than in normal goats. The concentrations of thiamphenicol in milk were significantly lower in Pasteurella multocida infected goats than in normal goats. The mean peak urine concentrations of thiamphenicol were reached 4 hours after each intramuscular dose with a lower significant concentration in Pasteurella multocida infected goats than in normal goats.
\end{abstract}

Keywords: Pharmacokinetics; Thiamphenicol; Pasteurella multocida; Lactating Goats.

\section{Introduction}

Thiamphenicol is a derivative of chloramphenicol, in which the aromatic P- nitro group was replaced with amethyl sulphonyl group. It is chemically [d (+)-threo-2-dichloroacetamido-1-(4methyl sulphonylphenyl) propane -1, 3-diol] (Mengozzi et al 2002). One reason for major interest in thiamphenicol is unlike chloramphenicol as it lacks the $\mathrm{p}$ nitro group, it does not induce irreversible bone marrow aplasia and aplastic anaemia ( $\mathrm{Li}$ et al. 2002). It is generally recognized that thiamphenicol possess an essential bacteriostatic activity by binding to the 50S subunits of ribosomes to block peptidyl transferase, hence inhibiting the extension of peptide chain and synthesis of bacterial protein (Turton et al .2000 , Turton et al. 2002 ). It is a broad spectrum antibacterial act on Gram-negative and Gram-positive bacteria involved in upper and lower respiratory tract infections, evoked by most Staphylococcus aureus, Streptococcus pneumoniae, Streptococcus pyogenes, and Moraxella catharralis as well as anaerobes, ( Mengozzi et al. 2002, Tullio et al. 2004).

Clinical pharmacology of thiamphenicol was investigated in sheep (Abdennebi and Stowe 1994), beef and dairy cattle (Abdennebi et al $.1994 \mathrm{~b}$ ), pre ruminant lambs and calves ( Mengozzi et al. 2002), camels ( Al Nazawi 2005) and in male goats ( Bogazil and Tohamy 2015) .

\section{Materials and methods}

\subsection{Drug}

Thiamphenicol was used in this study under the trade name $\left(\operatorname{Tirsan}^{\circledR}\right)$, which is manufactured by FATRO S.P.A. Italy. The vial about $100 \mathrm{ml}$, each $1 \mathrm{ml}$ of product contains $250 \mathrm{mg}$ thiamphenicol base.

\subsection{Experimental animals}

Four clinically normal lactating baladi goats and four experimentally infected goats and were used in this investigation. The body weight and age of the tested goats ranged from $20-26 \mathrm{~kg}$ and from 2 to 3 years old (for normal goats) and from $22-29 \mathrm{~kg}$ and from 2.5 to be 3.5 years old for experimentally infected goats. They were housed in hygienic stable fed on barseem, drawa and concentrate. Water was provided ad-libitum.

Grouping of goats:

Group (1):

It included 4 normal post-partum lactating goats. Each goat was injected intravenously into the left jugular vein with thiamphenicol ( $30 \mathrm{mg} / \mathrm{kg} \mathrm{b.wt)}$

These goats were left for 15 days after the intravenous injection to insure complete excretion of thiamphenicol from bodies of goats. Then each goat was injected intramuscularly into the gluteus medius muscle with the same dose of thiamphenicol.The aim of in- 
tramuscular injection to calculate the bioavailability of thiamphenicol in normal goats.

Group (2):

It included 4 normal post-partum lactating goats. Each goat was injected intramuscularly into the gluteus medius muscle with 30 $\mathrm{mg} / \mathrm{kg}$ b.wt thiamphenicol once dialy for five consecutive days. Group (3):

It included 4 experimentally infected post-partum lactating goats with Pasteurella multocida, which was sub cultured according to Zamir -saad and Shafarin (2007) into blood agar at $37{ }^{\circ} \mathrm{c}$ for 24 hours then uniform sized colonies were selected and cultured into brain heart infusion broth and incubated for 16 hours at $37 \mathrm{oc}$. The vaiable count was adjusted by Macferland tube to obtain concentration of $1 \times 10^{9}$ micro-organisms/ml. The The infecting dose for each lactating goat was $1 \mathrm{ml}$ subcutaneously in the dorsolateral side of the neck. The clinical symptoms of bacteraemia as fever and nasal discharge, appeared after 48-72 hours of injection with Pasteurella multocida suspension. Each goat was injected intra-

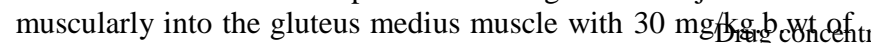
thiamphenicol,48 hours after experimental infection_with Pasteurella multocida once dialy for five consecutive days.

\subsection{Collection of samples}

\subsubsection{Blood samples}

Drug con

Blood samples were collected from right jugular vein following a single intravenous injection of thiamphenicol in normal goats blood samples were collected after $5 \mathrm{~min}, 10 \mathrm{~min}, 0.25,0.50,1,2$, $4,8,12$ and 24 hours of administration. Samples following the second, third, fourth and fifth intramuscular doses were collected before and $0.25,0.50,1,2,4,8,12$ and 24hours post injection. Blood samples taken from goats were allowed to clot and the serum separated by centrifugation, collected and divided in to two parts, the first part was used for assay of thiamphenicol and the second part was used for creatinine assay. All serum samples were stored at $-20^{\circ} \mathrm{C}$ until assay for thiamphenicol and creatinine.

\subsubsection{Urine samples}

The urine sample was taken by using rubber balloon catheter 41.585.12). The goats were catheterized and bladder was evacuated before each experiment. Following injection of thiamphenicol (single intravenous, single intramuscular and repeated intramuscular administration ) in goats (normal and experimentally infected), urine samples were taken after $0.25,0.50,1,2,4,8,12,24,36$ and 48 hours of administrations. Urine sample which was taken at $0.25 \mathrm{~h}$ was discarded. Urine samples trom goats of group (1) group (2), group (3) were collected and divided into two parts the first part was used for assay of thiamphenicol, and the second part was used for creatinine assay. All urine samples were stored at $-20^{\circ} \mathrm{C}$ until assay for thiamphenicol. After the end of each experiment, the urinary bladder was irrigated with 15 milliliters potassium permanganate solution 1: 5000 as antiseptic agent.

\subsubsection{Milk samples}

The udder was completely evacuated before drug administration and milk samples were collected by hand stripping from both teats. Following injection of thiamphenicol (single intravenous, single intramuscular and repeated intramuscular administration ) in goats (normal and experimentally infected), milk samples were taken after $0.50,1,2,4,8,12,24,36$ and 48 hours of administrations. Milk sample which was taken at $0.25 \mathrm{~h}$ was discarded the udder of each goat in all groups was completely evacuated before drug administration and after each milk sample. Milk samples from goats of all groups were allowed to clot (by mixing equal volumes of milk and 25\% trichloroacetic acid) and centrifuged. The skim milk was collected and stored at $-20^{\circ} \mathrm{C}$ until assay for thiamphenicol.

\subsection{Analytical procedure}

\subsubsection{Assay of thiamphenicol}

Thiamphenicol was assayed in goat's serum, installed water and goat's milk by microbiological method using agar well diffusion method by using of Bacillus Subtillis ATCC (American type culture collection 6633) as tested microorganism, which was obtained from Microbiological Depart- ment, Animal Health Institute, Doky, Giza, Egypt. According to (Arret et al. 1971)

\subsubsection{Assay of samples}

According to Grove and Randall (1955), three plates were used for each sample. Six pores were made; three of them were filled with reference concentration while the other three pores were filled with the serum, milk or urine samples in triplicate manner. The plates were incubated at $37^{\circ} \mathrm{C}$ for 18 hours then the diameter of inhibitory zones were measured. The diameter of inhibitory zones of samples were corrected by using the zone diameter of the reference concentration in the same manner as previously discussed either by addition or subtraction. From the standard curve, the concentrations corresponding to the corrected values of the inhibitory zones were obtained.

\subsection{Drug clearance}

Clearance of the tested drug from the blood of goats was estimated according to the following equation:

Drug concentration in urine $(\mu \mathrm{g} / \mathrm{ml}) \mathrm{X}$ Rate of diuresis $(\mathrm{ml} / \mathrm{min})$ Body weight $(\mathrm{Kg})$

Drug concentration in serum $(\mu \mathrm{g} / \mathrm{ml}) \mathbf{X}$

$$
10
$$

\subsection{Assay of creatinine in serum and urine}

Creatinine was assayed according to the method of Murray (1984) and performed by kit manufactured by Diamond diagnostics company, Egypt.

\subsubsection{Creatinine clearance}

The creatinine clearance (ml/min./10 kg.b.w.t) for goats was calculated by the following equation:

conncentration in urine $(\mathrm{mg} / \mathrm{L}) \mathrm{X}$ Rate of diuresis $(\mathrm{ml} / \mathrm{min})$

Body weight $(\mathrm{Kg})$

concentration in serum $(\mathrm{mg} / \mathrm{L}) \mathbf{X}$

\subsection{Pharmacokinetic analysis}

The pharmacokinetic parameters were calculated by using Winonlin, version 1.2 and other parameters according to Baggot $(1978 \mathrm{a} \& \mathrm{~b})$

\subsection{Statistical Analysis}

The data were calculated as mean \pm standard error. All statistical analysis were carried out according to Snedecor and Cochran (1980) using the scientific calculator CASIO fx 120.

\section{Results}

Following a single intravenous injection of $30 \mathrm{mg}$ thiamphenicol $/ \mathrm{kg}$ b.wt. in normal goats, thiamphenicol could be detected therapeutically for 24 hours post intravenous injection. The serum concentration - time curve of thiamphenicol following intravenous injection showed that the drug obeyed a two compartments open model (Figure 1). The disposition kinetics of thiamphenicol following a single intravenous, intramuscular injection were recorded in table (1). 
Intramuscular injection of $30 \mathrm{mg}$ thiamphenicol per kilogram body weight once daily for five consecutive days in normal and Pasterulla multocida infected goats revealed a lower significant serum thiamphenicol concentration in Pasterulla multocida infected goats compared with normal goats(Table 2). The pharmacokinetic parameters of thiamphenicol after repeated intramuscular injection in normal were compared to those in Pasteurella multocida infected goats (Table 3) and (Figure 2\&3).

From comparison, it's found that: marked significant decrease in $\left(\mathrm{k}_{1}, \mathrm{~K}_{12}, \mathrm{~K}_{21}, \mathrm{~T}_{0.5(\alpha)}, \mathrm{T}_{0.5(\beta)}\right.$ $\mathrm{T}_{\max }$ and $\mathrm{CL}_{\text {tot }}$ in normal compared with infected goats, on the other hand a significant increase in $\mathrm{C}_{\max }, \mathrm{AUC}, \mathrm{C}^{0}, \mathrm{~B}$ and $\beta$ in normal compared with infected goats.

The highest concentrations of thiamphenicol in milk were recorded 4 hours after each intramuscular dose (Table 4) with a significant lower value in pasteurella multocida infected goats compared with normal goats. The calculated milk/serum concentrations ratios of thiamphenicol after repeated intramuscular injection(Table $5)$.
The amount of urine $(\mathrm{ml} / \mathrm{min})$ voided after repeated intramuscular injection of $30 \mathrm{mg} / \mathrm{kg}$ bwt. Once daily of thiamphenicol for five consecutive days in normal and experimentally pasteurella multocida infected goats were recorded in table (6). The mean peak urine concentrations of thiamphenicol (Table 7) were reached 4 hours after each intramuscular dose with a lower significant concentration in pasteurella multocida infected goats compared with normal goats. Urine/serum concentration ratios of thiamphenicol after repeated intramuscular injection in normal and experimentally pasteurella multocida infected goats were calculated and illustrated in table (8).Creatinineclearancee $(\mathrm{ml} / \mathrm{min} / 10$ kglbwt.)1expressing glomerular filtration raterfromnblood ofogoatsowasfshownsinatablew(9). Thelrate) of Tthiamphenicoliclearancel (ml/min/10 kglbwt.)1from blood of ogoatsowasfshownsinatablew (10). tTheeratio.betweentthiamphenicoliclearancelandecreatinine clearanceewasecalculated and cillustratediinutablee (11). table (11).

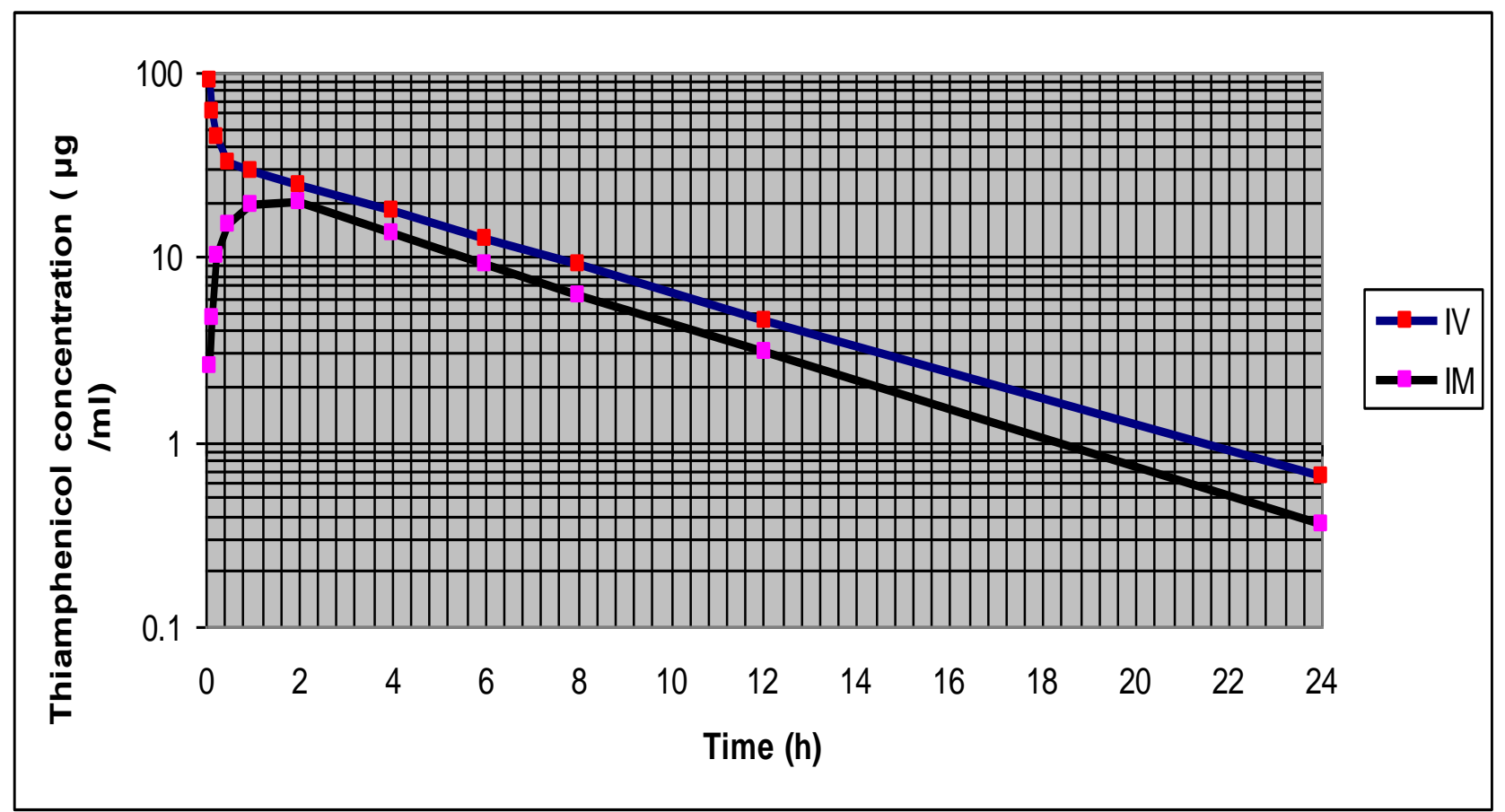

Fig. 1: Semilogarthmic Graph of Serum Concentrations of Thiamphenicol E (Mg/ Ml) in Normal Goats Following A Single Intramuscular Injection

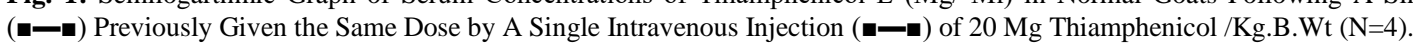

Table 1: Pharmacokinetics Parameters of Thiamphenicol Following A Single Intravenous and Intramusculer Injection of $30 \mathrm{Mg} / \mathrm{Kg} \mathrm{B}$. Wt in Normal Goats $(\mathrm{N}=4)$

\begin{tabular}{|c|c|c|c|}
\hline & & Intravenous & Intramusculer \\
\hline Parameters & Unit & ${ }^{-} \mathrm{X} \pm$ S.E(. & ${ }^{-} \mathrm{X} \pm$ S.E(. \\
\hline $\mathrm{C}^{\circ}$ & $\mu \mathrm{g} / \mathrm{ml}$ & $149.59 \pm 0.0868$ & -------- \\
\hline A & $\mu \mathrm{g} / \mathrm{ml}$ & $115.63 \pm 0.882$ & $71.25 \pm 0.837$ \\
\hline$\alpha$ & $\mathrm{h}^{-1}$ & $8.25 \pm 0.148$ & $0.875 \pm 0.004$ \\
\hline$) \alpha(0.5 \mathrm{~T}$ & $\mathrm{h}$ & $0.084 \pm 0.148$ & $0.791 \pm 0.003$ \\
\hline Tmax & $\mathrm{h}$ & -------------- & \pm 0.0241 .42 \\
\hline Cmax & $\mu \mathrm{g} / \mathrm{ml}$ & ----------- & $4.6116 .67 \pm$ \\
\hline $\mathrm{K}_{12}$ & $\mathrm{~h}^{-1}$ & $5.75 \pm 0.112$ & $0.221 \pm 0.007$ \\
\hline $\mathrm{K}_{21}$ & $\mathrm{~h}^{-1}$ & $2.06 \pm 0.036$ & $0.560 \pm 0.002$ \\
\hline $\mathrm{V}_{\mathrm{dss}}$ & $1 / \mathrm{kg}$ & $0.785 \pm 0.003$ & ----------- \\
\hline B & $\mu \mathrm{g} / \mathrm{ml}$ & $33.46 \pm 0.200$ & $24.47 \pm 0.289$ \\
\hline$\beta$ & $\mathrm{h}^{-1}$ & $0.167 \pm 0.003$ & $0.172 \pm 0.001$ \\
\hline $\mathrm{T}_{0.5(\beta)(}$ & lh & $4.15 \pm 0.083$ & $4.02 \pm 0.043$ \\
\hline $\mathrm{Cl}_{\text {tot }}$ & $1 / \mathrm{kg} / \mathrm{h}$ & $0.002 \pm 0.0002$ & $0.043 \pm 0.005$ \\
\hline AUMC & $\mu \mathrm{g} / \mathrm{ml} / \mathrm{h}$ & $1219.29 \pm 1.65$ & -------- \\
\hline MRT & $\mathrm{h}$ & $5.65 \pm 0.030$ & -------- \\
\hline AUC & $\mu \mathrm{g} / \mathrm{ml} / \mathrm{h}$ & $214.70 \pm 1.40$ & $250.8 \pm 8.47$ \\
\hline $\mathrm{F}$ & $\%$ & ------- & $66.63 \pm 0.813$ \\
\hline $\mathrm{K}_{01}$ & $h^{-1}$ & -------- & $1.11 \pm 0.016$ \\
\hline $\mathrm{T}_{0.5(\mathrm{k} 01}$ & $\mathrm{h}^{-1}$ & -------- & $0.625 \pm 0.009$ \\
\hline
\end{tabular}


$\mathrm{C}^{\circ}$ Drug concentration in the serum at zero time immediately after a single intravenous injection $(\mu \mathrm{g} / \mathrm{ml})$. A \& B: Zero time plasma drug concentration intercepts of biphasic intravenous disposition curve. The coefficient B is based on the terminal exponential phase ( $\mu \mathrm{g} / \mathrm{ml})$. $\alpha \& \beta$ : Hybrid rate constant of biphasic intravenous disposition curve values of $\alpha$ and $\beta$ are related to the slopes of distribution and elimination phase respectively, of biexponential drug disposition curve $\left(\mathrm{h}^{-1}\right)$. T0.5 $(\alpha)$ : Distribution half - life $(\mathrm{h})$. t0.5 $(\beta)$ : Elimination half life (h). K12: First - order transfer rate constant for drug distribution from Central to peripheral compartment (h-1). K21: First order transfer rate constant for drug distribution from Peripheral to central compartment $\left(\mathrm{h}^{-1}\right)$. $\mathrm{V}_{\mathrm{dss}}$ : The apparent volume of distribution which was calculated by steady - state method (ml/kg). AUMC: Area under moment curve. MRT: Mean residence time. AUC: Total area under the serum drug concentration versus time curve from $t=0$ to $t=\alpha$ after administration of a single dose.F: Bioavailability. Cmax: maximum drug concentration; Tmax: time of maximum observed concentration in blood.

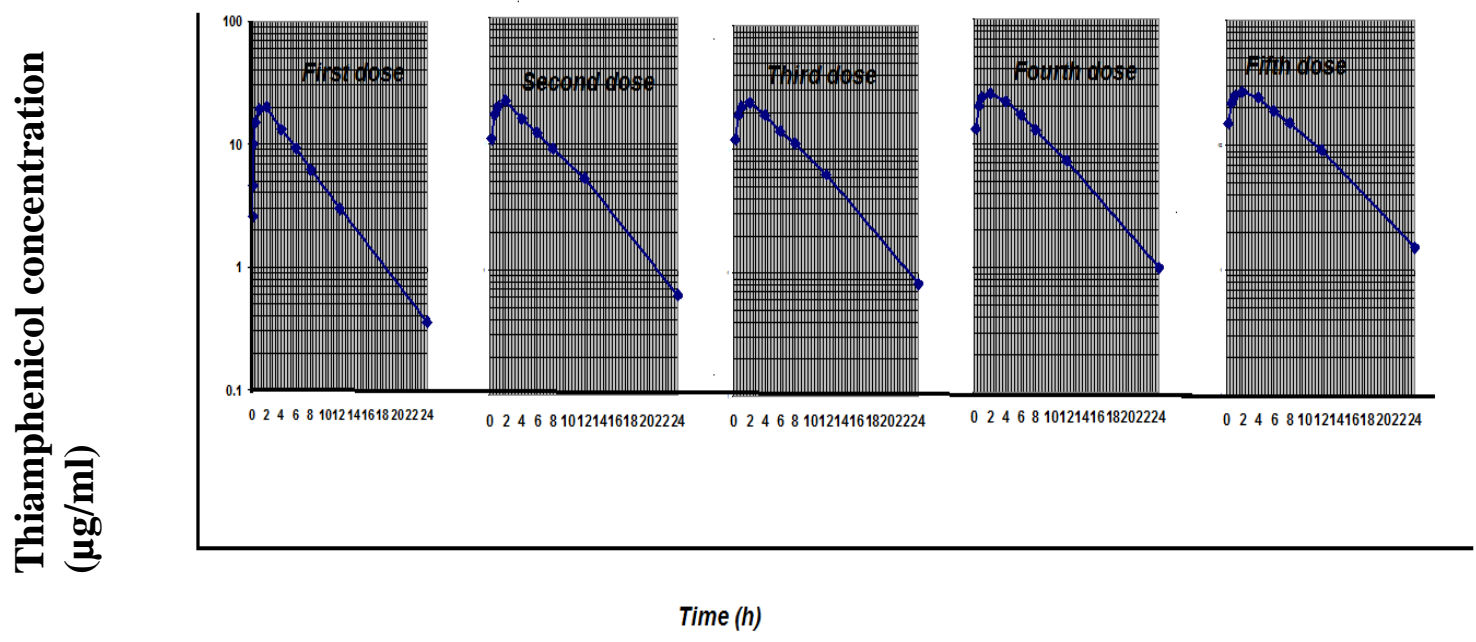

Fig. 2: Semilogarthmic Graph Depicting the Time Course of Thiamphenicol in Serum of Normal Goats Following Repeated Intramuscular Injection of $30 \mathrm{Mg}$ Thiamphenicol /Kg.B.Wt. Once Dialy for Five Consecutive Days. (N=4).

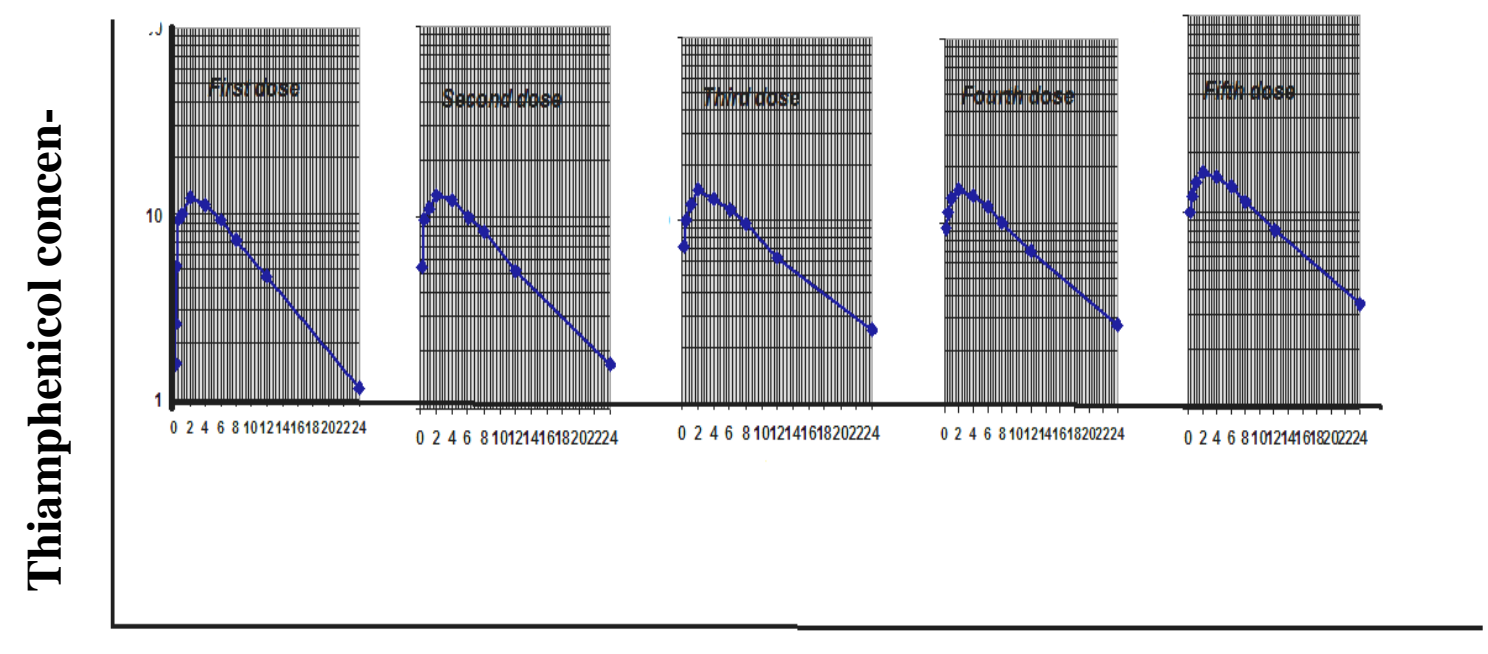

Time (h)

Fig. 3: Semilogarthmic Graph Depicting the Time Course of Thiamphenicol in Serum of Experimentally Pastuerella multocida Infected Goats Following Repeated Intramusculer Injection of $30 \mathrm{Mg}$ Thiamphenicol /Kg.B.Wt. Once Dialy for Five Consecutive Days. (N=4) 
Table 2: Serum Concentrations of Thiamphenicol in Normal and Experimentally Pasteurella multocida Infected Goats Following Repeated Intramuscular Injection of $30 \mathrm{Mg}$ Thiamphenicol /Kg.B.Wt. Once Daily for Five Consecutive Days $(\mathrm{N}=4)$

\begin{tabular}{|c|c|c|c|c|c|c|c|c|c|c|}
\hline \multirow[t]{2}{*}{$\begin{array}{l}\text { Time of } \\
\text { admin- } \\
\text { istration } \\
\text { (h) }\end{array}$} & \multicolumn{2}{|l|}{$(\mathrm{X} \pm$ S. E. $)$} & \multicolumn{2}{|l|}{$\overline{(X \pm S . ~ E .)}$} & $\begin{array}{l}\text { Third } \\
\text { ( } \mathrm{X} \pm \text { S. E.) }\end{array}$ & & \multicolumn{2}{|l|}{$\begin{array}{l}\text { Fourth } \\
(\bar{X} \pm \text { S. E.) }\end{array}$} & \multicolumn{2}{|l|}{$\begin{array}{l}\text { Fifth } \\
\overline{(X \pm S . ~ E .)}\end{array}$} \\
\hline & $\mathrm{N}$ & $\mathrm{I}$ & $\mathrm{N}$ & I & $\mathrm{N}$ & I & $\mathrm{N}$ & I & $\mathrm{N}$ & I \\
\hline 0.083 & $\begin{array}{l}2.57 \pm 0.2 \\
17\end{array}$ & $\begin{array}{l}1.57 \pm 0.047 \\
* *\end{array}$ & --------- & --------- & ------- & ----- & ------ & ----- & --------- & ------- \\
\hline 0.167 & $\begin{array}{l}4.60 \pm 0.3 \\
18\end{array}$ & $\begin{array}{l}2.57 \pm 0.217 \\
* *\end{array}$ & & & & & ----- & ------- & ---------- & \\
\hline 0.25 & $\begin{array}{l}10.00 \pm 0 . \\
408\end{array}$ & $\begin{array}{l}5.25 \pm 0.433 \\
* * *\end{array}$ & $\begin{array}{l}11.12 \pm 0 . \\
657\end{array}$ & $\begin{array}{l}5.50 \pm 0.204 \\
* * *\end{array}$ & $\begin{array}{l}12.12 \pm 0 . \\
718\end{array}$ & $\begin{array}{l}7.25 \pm 0.144 \\
* * *\end{array}$ & $\begin{array}{l}13.25 \pm 0 . \\
322\end{array}$ & $\begin{array}{l}9.25 \pm 0.322 \\
* * *\end{array}$ & $\begin{array}{l}15.00 \pm 0.40 \\
8\end{array}$ & $\begin{array}{l}10.00 \pm 0.40 \\
8 * * *\end{array}$ \\
\hline 0.50 & $\begin{array}{l}15.00 \pm 0 . \\
408\end{array}$ & $\begin{array}{l}9.25 \pm 0.322 \\
* * *\end{array}$ & $\begin{array}{l}17.00 \pm 0 . \\
408\end{array}$ & $9.62 \pm 0.125$ & $\begin{array}{l}19.00 \pm 0 . \\
707\end{array}$ & $\begin{array}{l}10.00 \pm 0.40 \\
8\end{array}$ & $\begin{array}{l}20.00 \pm 0 . \\
707\end{array}$ & $\begin{array}{l}11.25 \pm 0.47 \\
8\end{array}$ & $\begin{array}{l}22.00 \pm 0.40 \\
8\end{array}$ & $\begin{array}{l}12.00 \pm 0.40 \\
8\end{array}$ \\
\hline 1 & $\begin{array}{l}19.00 \pm 0 . \\
408\end{array}$ & $10 \pm 0.408$ & $\begin{array}{l}20.00 \pm 0 . \\
707\end{array}$ & $\begin{array}{l}11.12 \pm 0.65 \\
7\end{array}$ & $\begin{array}{l}22.00 \pm 0 . \\
408\end{array}$ & $\begin{array}{l}12.12 \pm 0.71 \\
8 * * *\end{array}$ & $\begin{array}{l}24.00 \pm 0 . \\
707\end{array}$ & $\begin{array}{l}13.50 \pm 0.20 \\
4 * * *\end{array}$ & $\begin{array}{l}25.00 \pm 0.40 \\
8\end{array}$ & $\begin{array}{l}14.00 \pm 0.40 \\
8 * * *\end{array}$ \\
\hline 2 & $\begin{array}{l}20.00 \pm 0 . \\
707\end{array}$ & $\begin{array}{l}12.25 \pm 0.77 \\
7 * * *\end{array}$ & $\begin{array}{l}22.00 \pm 0 . \\
408\end{array}$ & $\begin{array}{l}13.00 \pm 0.20 \\
4\end{array}$ & $\begin{array}{l}24.00 \pm 0 . \\
707\end{array}$ & $\begin{array}{l}14.75 \pm 0.47 \\
8\end{array}$ & $\begin{array}{l}25.00 \pm 0 . \\
408\end{array}$ & $\begin{array}{l}15.00 \pm 0.40 \\
8\end{array}$ & $\begin{array}{l}27.00 \pm 0.91 \\
2\end{array}$ & $\begin{array}{l}15.75 \pm 0.25 \\
0\end{array}$ \\
\hline 6 & $\begin{array}{l}9.25 \pm 0.3 \\
22\end{array}$ & $9.25 \pm 0.322$ & $\begin{array}{l}12.25 \pm 0 . \\
777\end{array}$ & $10 \pm 0.408$ & $\begin{array}{l}14.00 \pm 0 . \\
408\end{array}$ & $\begin{array}{l}11.50 \pm 0.61 \\
2\end{array}$ & $\begin{array}{l}17.00 \pm 0 . \\
408\end{array}$ & $\begin{array}{l}12.25 \pm 0.77 \\
7\end{array}$ & $\begin{array}{l}19.00 \pm 0.70 \\
7\end{array}$ & $\begin{array}{l}13.50 \pm 0.20 \\
4\end{array}$ \\
\hline 8 & $\begin{array}{l}6.25 \pm 0.4 \\
33\end{array}$ & $7.25 \pm 0.144$ & $\begin{array}{l}9.25 \pm 0.3 \\
22\end{array}$ & $8.37 \pm 0.314$ & $\begin{array}{l}11.12 \pm 0 \\
657\end{array}$ & $9.50 \pm 0.204$ & $\begin{array}{l}13.00 \pm 0 . \\
408\end{array}$ & $\begin{array}{l}10.00 \pm 0.40 \\
8 * * *\end{array}$ & $\begin{array}{l}15.00 \pm 0.40 \\
8\end{array}$ & $\begin{array}{l}11.25 \pm 0.47 \\
8 * * *\end{array}$ \\
\hline 12 & $\begin{array}{l}3.00 \pm 0.4 \\
08\end{array}$ & $\begin{array}{l}4.60 \pm 0.318 \\
* *\end{array}$ & $\begin{array}{l}5.25 \pm 0.4 \\
33\end{array}$ & $5.25 \pm 0.433$ & $\begin{array}{l}6.25 \pm 0.4 \\
33\end{array}$ & $6.25 \pm 0.433$ & $\begin{array}{l}7.25 \pm 0.1 \\
44\end{array}$ & $\begin{array}{l}7.00 \pm 0.353 \\
* * *\end{array}$ & $9.25 \pm 0.322$ & $\begin{array}{l}8.125 \pm 0.37 \\
5\end{array}$ \\
\hline 24 & $\begin{array}{l}0.570 \pm 0 . \\
010\end{array}$ & $\begin{array}{l}1.15 \pm 0.017 \\
* * *\end{array}$ & $\begin{array}{l}0.625 \pm 0 . \\
032\end{array}$ & $\begin{array}{l}1.70 \pm 0.020 \\
* * *\end{array}$ & $\begin{array}{l}0.812 \pm 0 \\
042\end{array}$ & $\begin{array}{l}2.53 \pm 0.074 \\
* * *\end{array}$ & $\begin{array}{l}1.00 \pm 0.0 \\
70\end{array}$ & $\begin{array}{l}2.75 \pm 0.086 \\
* * *\end{array}$ & $\begin{array}{l}1.52 \pm 0.047 \\
* * *\end{array}$ & $\begin{array}{l}3.40 \pm 0.040 \\
* * *\end{array}$ \\
\hline
\end{tabular}

* Between normal and Pasteurella multocida infected goats $\mathrm{N}=$ Normal $\mathrm{I}=$ infected $* \mathrm{P}<0.05 * * \mathrm{P}<0.01 * * * \mathrm{P}<0.001$

Table 3: Pharmacokinetic Parameters of Thiamphenicol $(\mu \mathrm{g} / \mathrm{Ml})$ in Normal and Experimentally Pasteurella multocida Infected Goats Following Repeated Intramuscular Injection of $30 \mathrm{Mg}$ Thiamphenicol $/ \mathrm{Kg}$. B. Wt. Once Daily or Five Consecutive Days $(\mathrm{N}=4)$

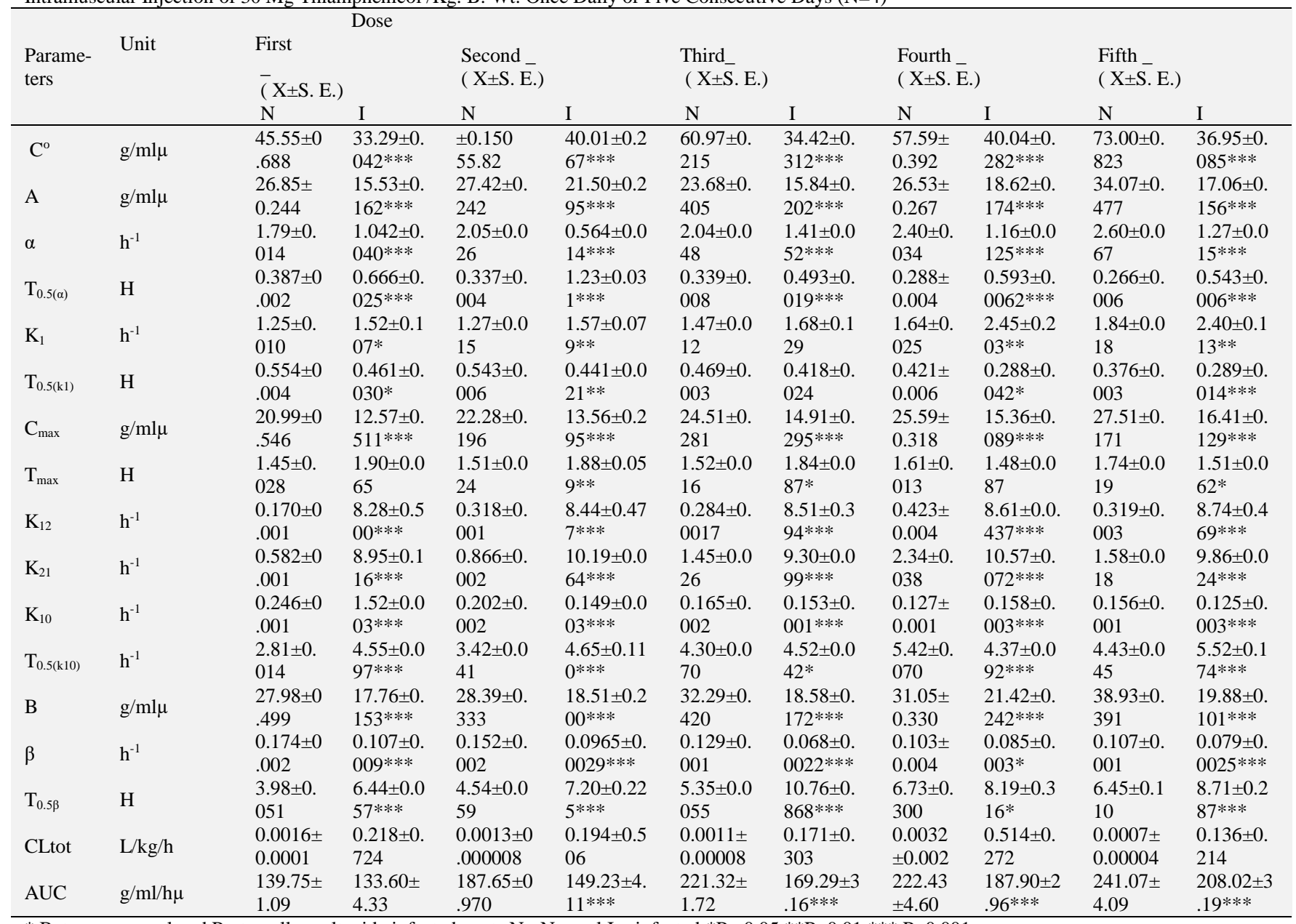

\footnotetext{
$*$ Between normal and Pasteurella multocida infected goats $\mathrm{N}=$ Normal $\mathrm{I}=$ infected $* \mathrm{P}<0.05 * * \mathrm{P}<0.01 * * * \mathrm{P}<0.001$
} 
Table 4: Milk Concentrations of Thiamphenicol ( $\mu \mathrm{g} / \mathrm{Ml})$ In Normal and Experimentally Pasteurella Multocida Infected Goats Following Repeated Intramuscular Injection of $30 \mathrm{Mg}$ Thiamphenicol $/ \mathrm{Kg}$.B.Wt. Once Daily For Five Consecutive Days (N=4)

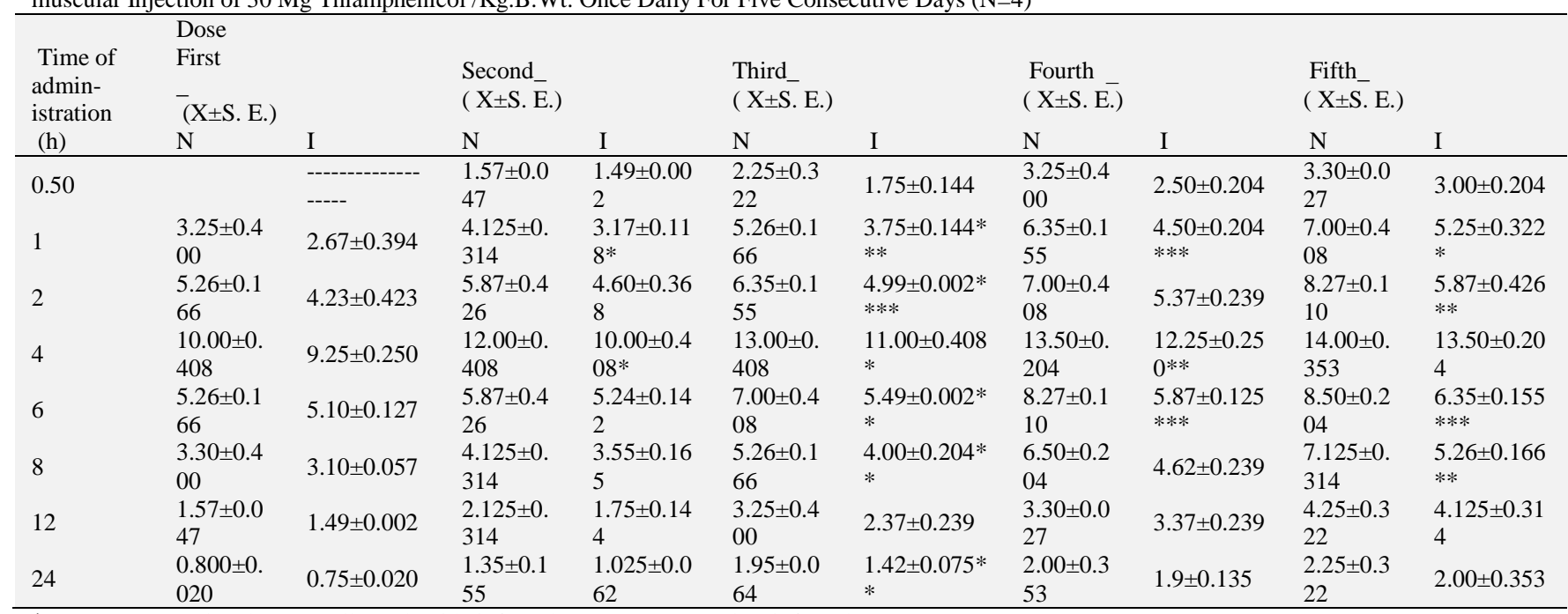

* Between normal and Pasteurella multocida infected goats. $\mathrm{N}=$ Normal $\mathrm{I}=$ infected $* \mathrm{P}<0.05 * * \mathrm{P}<0.01 * * * \mathrm{P}<0.001$.

Table 5: Milk/Serum Concentrations Ratios of Thiamphenicol ( $\mu \mathrm{g} / \mathrm{Ml})$ in Normal and Experimentally Pasteurella multocida Infected Goats Following Repeated Intramuscular Injection of $30 \mathrm{Mg}$ Thiamphenicol /Kg. B. Wt. Once Daily for Five Consecutive Days (N=4)

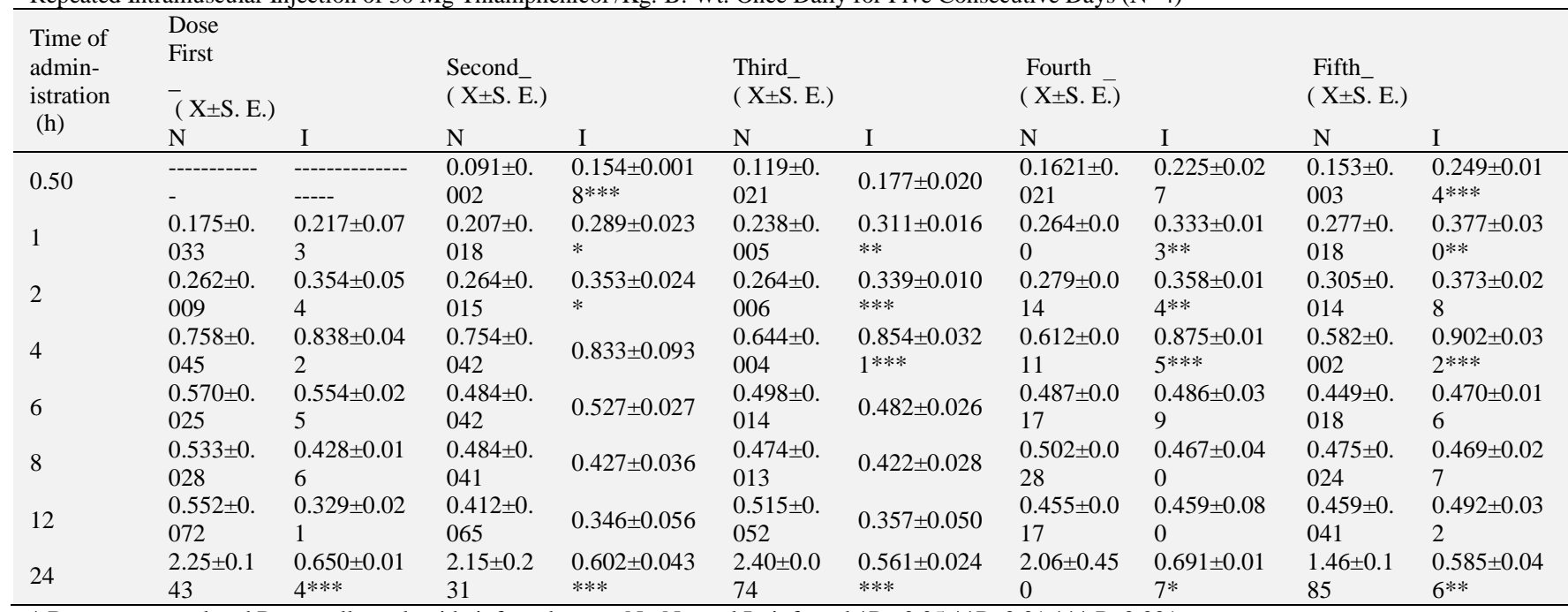

$*$ Between normal and Pasteurella multocida infected gaots. $\mathrm{N}=$ Normal $\mathrm{I}=$ infected $* \mathrm{P}<0.05 * * \mathrm{P}<0.01 * * * \mathrm{P}<0.001$

Table 6: The Amount of Urine (Ml/Min) Voided in Normal and Experimentally Pasteurella multocida Infected Goats Following Repeated Intramuscular Injection of $30 \mathrm{Mg}$ Thiamphenicol $/ \mathrm{Kg}$. B. Wt. Once Daily for Five Consecutive Days $(\mathrm{N}=4)$

\begin{tabular}{|c|c|c|c|c|c|c|c|c|c|c|}
\hline \multirow{2}{*}{$\begin{array}{l}\text { Time of } \\
\text { administra- } \\
\text { tion } \\
\text { (h) }\end{array}$} & \multicolumn{2}{|l|}{$\begin{array}{l}\text { First } \\
-(\mathrm{X} \pm \text { S. E. })\end{array}$} & \multicolumn{2}{|l|}{$\begin{array}{l}\text { Second } \\
(\mathrm{X} \pm \text { S. E.) }\end{array}$} & \multicolumn{2}{|l|}{$\begin{array}{l}\text { Third_- } \\
\text { ( X } \pm \text { S. E.) }\end{array}$} & \multicolumn{2}{|l|}{$\begin{array}{l}\text { Fourth } \\
(\mathrm{X} \pm \text { S. E.) }\end{array}$} & \multicolumn{2}{|l|}{$\begin{array}{l}\text { Fifth_- } \\
\text { ( X } \pm \text { S. E.) }\end{array}$} \\
\hline & $\mathrm{N}$ & I & $\mathrm{N}$ & I & $\mathrm{N}$ & I & $\mathrm{N}$ & I & $\mathrm{N}$ & I \\
\hline 0.50 & $\begin{array}{l}0.423 \pm 0.0 \\
37\end{array}$ & $\begin{array}{l}0.408 \pm 0.03 \\
4\end{array}$ & $\begin{array}{l}0.474 \pm 0.0 \\
16\end{array}$ & 0.4580 .016 & $\begin{array}{l}0.508 \pm 0.0 \\
28\end{array}$ & $\begin{array}{l}0.491 \pm 0.02 \\
0\end{array}$ & $\begin{array}{l}0.616 \pm 0.02 \\
1\end{array}$ & $\begin{array}{l}0.616 \pm 0.0 \\
21\end{array}$ & $\begin{array}{l}0.733 \pm 0.0 \\
36\end{array}$ & $\begin{array}{l}0.733 \pm 0.0 \\
36\end{array}$ \\
\hline 1 & $\begin{array}{l}0.547 \pm 0.0 \\
17\end{array}$ & $\begin{array}{l}0.554 \pm 0.01 \\
9\end{array}$ & $\begin{array}{l}0.617 \pm 0.0 \\
45\end{array}$ & $\begin{array}{l}0.579 \pm 0.02 \\
9\end{array}$ & $\begin{array}{l}0.629 \pm 0.0 \\
71\end{array}$ & $\begin{array}{l}0.674 \pm 0.08 \\
0\end{array}$ & $\begin{array}{l}0.683 \pm 0.03 \\
7\end{array}$ & $\begin{array}{l}0.704 \pm 0.0 \\
71\end{array}$ & $\begin{array}{l}0.791 \pm 0.0 \\
53\end{array}$ & $\begin{array}{l}0.807 \pm 0.0 \\
63\end{array}$ \\
\hline 2 & $\begin{array}{l}0.614 \pm 0.0 \\
18\end{array}$ & $\begin{array}{l}00.645 \pm 0.0 \\
26\end{array}$ & $\begin{array}{l}0.679 \pm 0.0 \\
22\end{array}$ & $\begin{array}{l}0.6455 \pm 0.0 \\
26\end{array}$ & $\begin{array}{l}0.692 \pm 0.0 \\
15\end{array}$ & $\begin{array}{l}0.693 \pm 0.01 \\
5\end{array}$ & $\begin{array}{l}0.718 \pm 0.01 \\
0\end{array}$ & $\begin{array}{l}0.718 \pm 0.0 \\
10\end{array}$ & $\begin{array}{l}0.749 \pm 0.0 \\
16\end{array}$ & $\begin{array}{l}0.749 \pm 0.0 \\
16\end{array}$ \\
\hline 4 & $\begin{array}{l}0.765 \pm 0.0 \\
37\end{array}$ & $\begin{array}{l}0.739 \pm 0.03 \\
5\end{array}$ & $\begin{array}{l}0.812 \pm 0.0 \\
14\end{array}$ & $\begin{array}{l}0.770 \pm 0.02 \\
6\end{array}$ & $\begin{array}{l}0.831 \pm 0.0 \\
17\end{array}$ & $\begin{array}{l}0.843 \pm 0.03 \\
5\end{array}$ & $\begin{array}{l}0.892 \pm 0.02 \\
3\end{array}$ & $\begin{array}{l}0.874 \pm 0.0 \\
16\end{array}$ & $\begin{array}{l}0.983 \pm 0.0 \\
25\end{array}$ & $\begin{array}{l}0.983 \pm 0.0 \\
25\end{array}$ \\
\hline 6 & $\begin{array}{l}0.673 \pm 0.0 \\
16\end{array}$ & $\begin{array}{l}0.647 \pm 0.02 \\
9\end{array}$ & $\begin{array}{l}0.781 \pm 0.0 \\
15\end{array}$ & $\begin{array}{l}0.731 \pm 0.02 \\
8\end{array}$ & $\begin{array}{l}0.781 \pm 0.0 \\
23\end{array}$ & $\begin{array}{l}0.770 \pm 0.01 \\
3\end{array}$ & $\begin{array}{l}0.791 \pm 0.01 \\
9\end{array}$ & $\begin{array}{l}0.777 \pm 0.0 \\
19\end{array}$ & $\begin{array}{l}0.796 \pm 0.0 \\
24\end{array}$ & $\begin{array}{l}0.792 \pm 0.0 \\
19\end{array}$ \\
\hline 8 & $\begin{array}{l}0.567 \pm 0.0 \\
06\end{array}$ & $\begin{array}{l}0.567 \pm 0.00 \\
6\end{array}$ & $\begin{array}{l}0.599 \pm 0.0 \\
05\end{array}$ & $\begin{array}{l}0.588 \pm 0.01 \\
5\end{array}$ & $\begin{array}{l}0.589 \pm 0.0 \\
09\end{array}$ & $\begin{array}{l}0.562 \pm 0.01 \\
2\end{array}$ & $\begin{array}{l}0.631 \pm 0.00 \\
5\end{array}$ & $\begin{array}{l}0.624 \pm 0.0 \\
08\end{array}$ & $\begin{array}{l}0.645 \pm 0.0 \\
04\end{array}$ & $\begin{array}{l}0.655 \pm 0.0 \\
05\end{array}$ \\
\hline 12 & $\begin{array}{l}0.436 \pm 0.0 \\
16\end{array}$ & $\begin{array}{l}0.440 \pm 0.01 \\
1\end{array}$ & $\begin{array}{l}0.474 \pm 0.0 \\
09\end{array}$ & $\begin{array}{l}0.474 \pm 0.00 \\
9\end{array}$ & $\begin{array}{l}0.480 \pm 0.0 \\
08\end{array}$ & $\begin{array}{l}0.0451 \pm 0.0 \\
13\end{array}$ & $\begin{array}{l}0.487 \pm 0.00 \\
14\end{array}$ & $\begin{array}{l}0.482 \pm 0.0 \\
15\end{array}$ & $\begin{array}{l}0.548 \pm 0.0 \\
07\end{array}$ & $\begin{array}{l}0.655 \pm 0.0 \\
04\end{array}$ \\
\hline 24 & $\begin{array}{l}0.367 \pm 0.0 \\
08\end{array}$ & $\begin{array}{l}0.369 \pm 0.00 \\
7\end{array}$ & $\begin{array}{l}0.450 \pm 0.0 \\
16\end{array}$ & $\begin{array}{l}0.242 \pm 0.01 \\
1\end{array}$ & $\begin{array}{l}0.433 \pm 0.0 \\
03\end{array}$ & $\begin{array}{l}0.383 \pm 0.04 \\
7\end{array}$ & $\begin{array}{l}0.443 \pm 0.00 \\
3\end{array}$ & $\begin{array}{l}0.440 \pm 0.0 \\
02\end{array}$ & $\begin{array}{l}0.552 \pm 0.0 \\
29\end{array}$ & $\begin{array}{l}0.531 \pm 0.0 \\
42\end{array}$ \\
\hline
\end{tabular}


Table 7: Urine Concentrations of Thiamphenicol $(\mu \mathrm{g} / \mathrm{Ml})$ in Normal and Experimentally Pasteurella Multocida Infected Goats Following Repeated Intramuscular Injection of $30 \mathrm{Mg}$ Thiamphenicol $/ \mathrm{Kg}$. B. Wt. Once Daily for Five Consecutive Days $(\mathrm{N}=4)$

\begin{tabular}{|c|c|c|c|c|c|c|c|c|c|c|}
\hline \multirow[t]{2}{*}{$\begin{array}{l}\text { Time of } \\
\text { admin- } \\
\text { istration } \\
\text { (h) }\end{array}$} & \multicolumn{2}{|l|}{$\begin{array}{l}\text { First } \\
\overline{(} \mathrm{X} \pm \text { S. E. })\end{array}$} & \multicolumn{2}{|l|}{$\begin{array}{l}\text { Second } \\
(\mathrm{X} \pm \text { S. E.) }\end{array}$} & \multicolumn{2}{|l|}{ 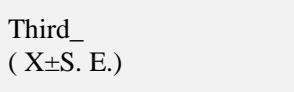 } & \multicolumn{2}{|l|}{$\begin{array}{l}\text { Fourth } \\
(\mathrm{X} \pm \text { S. E.) }\end{array}$} & \multicolumn{2}{|l|}{$\begin{array}{l}\text { Fifth- } \\
(\mathrm{X} \pm \text { S. E.) }\end{array}$} \\
\hline & $\mathrm{N}$ & $\mathrm{I}$ & $\mathrm{N}$ & I & $\mathrm{N}$ & $\mathrm{I}$ & $\mathrm{N}$ & I & $\mathrm{N}$ & $\mathrm{I}$ \\
\hline 0.50 & $\begin{array}{l}111.50 \pm 2 \\
.59\end{array}$ & $\begin{array}{l}90.00 \pm 1.73 \\
* * *\end{array}$ & $\begin{array}{l}117.75 \pm 2 \\
.25\end{array}$ & $\begin{array}{l}106.50 \pm 4.5 \\
0\end{array}$ & $\begin{array}{l}131.25 \pm 7 \\
.10\end{array}$ & $\begin{array}{l}113.00 \pm 2.2 \\
5 *\end{array}$ & $\begin{array}{l}138.75 \pm 3 \\
.75\end{array}$ & $\begin{array}{l}115.50 \pm 2.5 \\
9 * *\end{array}$ & $\begin{array}{l}148.50 \pm 9 \\
.20\end{array}$ & $\begin{array}{l}119.25 \pm 3.0 \\
9 *\end{array}$ \\
\hline 1 & $\begin{array}{l}131.25 \pm 7 \\
.18\end{array}$ & $\begin{array}{l}102.00 \pm 5.1 \\
9 *\end{array}$ & $\begin{array}{l}138.75 \pm 3 \\
.75\end{array}$ & $\begin{array}{l}115.50 \pm 2.5 \\
9 * *\end{array}$ & $\begin{array}{l}141.75 \pm 9 \\
.02\end{array}$ & $\begin{array}{l}117.00 \pm 2.2 \\
5 *\end{array}$ & $\begin{array}{l}162.00 \pm 6 \\
.92\end{array}$ & $\begin{array}{l}123.75 \pm 3.7 \\
5 * *\end{array}$ & $\begin{array}{l}169.50 \pm 6 \\
.65\end{array}$ & $\begin{array}{l}126.75 \pm 3.0 \\
9 * *\end{array}$ \\
\hline 2 & $\begin{array}{l}163.50 \pm 7 \\
.88\end{array}$ & $\begin{array}{l}113.25 \pm 2.2 \\
5 * * *\end{array}$ & $\begin{array}{l}181.50 \pm 3 \\
.77\end{array}$ & $\begin{array}{l}117.00 \pm 2.2 \\
5 * * *\end{array}$ & $\begin{array}{l}186.00 \pm 3 \\
.46\end{array}$ & $\begin{array}{l}125.25 \pm 3.5 \\
4 * * *\end{array}$ & $\begin{array}{l}192.00 \pm 4 \\
.89\end{array}$ & $\begin{array}{l}131.25 \pm 7.1 \\
8 * * *\end{array}$ & $\begin{array}{l}198.00 \pm 3 \\
.46\end{array}$ & $\begin{array}{l}138.75 \pm 3.7 \\
5 * * *\end{array}$ \\
\hline 4 & $\begin{array}{l}241.50 \pm 3 \\
.57\end{array}$ & $\begin{array}{l}123.75 \pm 3.7 \\
5 * * *\end{array}$ & $\begin{array}{l}249.75 \pm 7 \\
.48\end{array}$ & $\begin{array}{l}131.25 \pm 7.1 \\
8 * * *\end{array}$ & $\begin{array}{l}258.00 \pm 7 \\
.34\end{array}$ & $\begin{array}{l}138.75 \pm 3.7 \\
5 * * *\end{array}$ & $\begin{array}{l}265.5 \pm 8 \\
61\end{array}$ & $\begin{array}{l}146.25 \pm 3.7 \\
5 * * *\end{array}$ & $\begin{array}{l}270.00 \pm 7 \\
.34\end{array}$ & $\begin{array}{l}158.25 \pm 9.5 \\
9 * * *\end{array}$ \\
\hline 6 & $\begin{array}{l}78.00 \pm 1 . \\
73\end{array}$ & $\begin{array}{l}72.00 \pm 1.73 \\
*\end{array}$ & $\begin{array}{l}79.50 \pm 1 . \\
50\end{array}$ & $78.00 \pm 1.73$ & $\begin{array}{l}82.4 \pm 3.7 \\
7\end{array}$ & $79.50 \pm 1.50$ & $\begin{array}{l}84.00 \pm 1 . \\
73\end{array}$ & $\begin{array}{l}80.25 \pm 0.75 \\
0\end{array}$ & $\begin{array}{l}87.00 \pm 2 . \\
44\end{array}$ & $84.00 \pm 1.73$ \\
\hline 8 & $\begin{array}{l}42.75 \pm 1 \\
88\end{array}$ & $\begin{array}{l}37.50 \pm 0.86 \\
6 *\end{array}$ & $\begin{array}{l}48.00 \pm 2 . \\
24\end{array}$ & $42.75 \pm 1.88$ & $\begin{array}{l}49.50 \pm 1 . \\
50\end{array}$ & $48.00 \pm 4.42$ & $\begin{array}{l}54.00 \pm 2 . \\
44\end{array}$ & $54.00 \pm 2.44$ & $\begin{array}{l}58.50 \pm 2 . \\
87\end{array}$ & $57.00 \pm 1.73$ \\
\hline 12 & $\begin{array}{l}19.50 \pm 2 . \\
87\end{array}$ & $17.25 \pm 1.43$ & $\begin{array}{l}21.00 \pm 2 . \\
12\end{array}$ & $18.00 \pm 1.73$ & $\begin{array}{l}23.4 \pm 1.3 \\
6\end{array}$ & $19.50 \pm 2.87$ & $\begin{array}{l}24.15 \pm 1 \\
10\end{array}$ & $22.50 \pm 1.50$ & $\begin{array}{l}25.50 \pm 0 . \\
866\end{array}$ & $24.15 \pm 1.10$ \\
\hline 24 & $\begin{array}{l}5.85 \pm 1.1 \\
3\end{array}$ & $4.20 \pm 0.173$ & $\begin{array}{l}8.1 \pm 0.71 \\
4\end{array}$ & $5.85 \pm 1.13$ & $\begin{array}{l}9.30 \pm 0.1 \\
73\end{array}$ & $6.75 \pm 0.75^{*}$ & $\begin{array}{l}9.45 \pm 0.1 \\
50\end{array}$ & $9.00 \pm 1.22$ & $\begin{array}{l}9.90 \pm 0.1 \\
73\end{array}$ & $\begin{array}{l}9.30 \pm 0.173 \\
*\end{array}$ \\
\hline
\end{tabular}

* Between normal and Pasteurella multocida infected goats. $\mathrm{N}=$ Normal $\mathrm{I}=$ infected $* \mathrm{P}<0.05 * * \mathrm{P}<0.01 * * * \mathrm{P}<0.001$

Table 8: Urine/Serum Concentrations Ratios of Thiamphenicol ( $\mu \mathrm{g} / \mathrm{Ml})$ in Normal and Experimentally Pasteurella multocida Infected Goats Following Repeated Intramuscular Injection of $30 \mathrm{Mg}$ Thiamphenicol /Kg.B.Wt. Once Daily for Five Consecutive Days (N=4)

\begin{tabular}{|c|c|c|c|c|c|c|c|c|c|c|}
\hline \multirow{2}{*}{$\begin{array}{l}\text { Time of } \\
\text { admin- } \\
\text { istration } \\
\text { (h) }\end{array}$} & $\begin{array}{l}\text { Dose } \\
\text { First } \\
-(\mathrm{X} \pm \text { S. E. })\end{array}$ & & $\begin{array}{l}\text { Second } \\
(\mathrm{X} \pm \text { S. E. }\end{array}$ & & $\begin{array}{l}\text { Third_- } \\
\text { ( } \mathrm{X} \pm \text { S. E.) }\end{array}$ & & $\begin{array}{l}\text { Fourth } \\
(\mathrm{X} \pm \text { S. E.) }\end{array}$ & & $\begin{array}{l}\text { Fifth_- } \\
(\mathrm{X} \pm \text { S. E. }\end{array}$ & \\
\hline & $\mathrm{N}$ & I & $\mathrm{N}$ & I & $\mathrm{N}$ & I & $\mathrm{N}$ & I & $\mathrm{N}$ & I \\
\hline 0.50 & $\begin{array}{l}7.72 \pm 0.3 \\
26\end{array}$ & $\begin{array}{l}9.78 \pm \\
0.517 *\end{array}$ & $\begin{array}{l}6.94 \pm 0 . \\
280\end{array}$ & $\begin{array}{l}11.06 \pm 0.448 \\
* * *\end{array}$ & $\begin{array}{l}6.93 \pm 0.4 \\
64\end{array}$ & $\begin{array}{l}11.35 \pm 0.327 \\
* * *\end{array}$ & $\begin{array}{l}6.98 \pm 0.4 \\
56\end{array}$ & $\begin{array}{l}10.31 \pm 0.42 \\
7 * *\end{array}$ & $\begin{array}{l}6.75 \pm 0.4 \\
70\end{array}$ & $\begin{array}{l}9.98 \pm 0.517 \\
* *\end{array}$ \\
\hline 1 & $\begin{array}{l}7.07 \pm 0.6 \\
92\end{array}$ & $\begin{array}{l}10.20 \pm 0.370 \\
* *\end{array}$ & $\begin{array}{l}6.95 \pm 0 . \\
234\end{array}$ & $\begin{array}{l}10.48 \pm 0.644 \\
* *\end{array}$ & $\begin{array}{l}6.92 \pm 0.4 \\
22\end{array}$ & $\begin{array}{l}10.48 \pm 0.647 \\
* *\end{array}$ & $\begin{array}{l}6.74 \pm 0.1 \\
73\end{array}$ & $\begin{array}{l}9.17 \pm 0.307 \\
* * *\end{array}$ & $\begin{array}{l}6.71 \pm 0.2 \\
36\end{array}$ & $\begin{array}{l}9.08 \pm 0.448 \\
* *\end{array}$ \\
\hline 2 & $\begin{array}{l}8.18 \pm 0.3 \\
85\end{array}$ & $9.35 \pm 0.617$ & $\begin{array}{l}8.24 \pm 0 \\
039\end{array}$ & $8.64 \pm 1.79$ & $\begin{array}{l}7.76 \pm 0.2 \\
14\end{array}$ & $\begin{array}{l}8.50 \pm 0.206^{*} \\
* *\end{array}$ & $\begin{array}{l}7.69 \pm 0.3 \\
22\end{array}$ & $8.78 \pm 0.618$ & $\begin{array}{l}7.34 \pm 0.1 \\
34\end{array}$ & $\begin{array}{l}8.80 \pm 0.224 \\
* *\end{array}$ \\
\hline 4 & $\begin{array}{l}18.27 \pm 0 . \\
685\end{array}$ & $\begin{array}{l}11.27 \pm 0.908 \\
* * *\end{array}$ & $\begin{array}{l}15.75 \pm 1 \\
.19\end{array}$ & $10.96 \pm 1.11^{*}$ & $\begin{array}{l}13.60 \pm 0 . \\
369\end{array}$ & $\begin{array}{l}10.66 \pm 0.177 \\
* * *\end{array}$ & $\begin{array}{l}12.07 \pm 0 . \\
441\end{array}$ & $\begin{array}{l}10.48 \pm 0.41 \\
7 *\end{array}$ & $\begin{array}{l}11.25 \pm 0 . \\
171\end{array}$ & $\begin{array}{l}10.58 \pm 0.74 \\
8\end{array}$ \\
\hline 6 & $\begin{array}{l}8.46 \pm 0.4 \\
14\end{array}$ & $8.45 \pm 0.717$ & $\begin{array}{l}6.55 \pm 0 . \\
33\end{array}$ & $7.85 \pm 0.464$ & $\begin{array}{l}5.92 \pm 0.4 \\
47\end{array}$ & $7.81 \pm 0.186^{*}$ & $\begin{array}{l}4.94 \pm 0.0 \\
85\end{array}$ & $\begin{array}{l}6.64 \pm 0.488 \\
*\end{array}$ & $\begin{array}{l}4.58 \pm 0.1 \\
39\end{array}$ & $\begin{array}{l}6.22 \pm 0.155 \\
* * *\end{array}$ \\
\hline 8 & $\begin{array}{l}6.14 \pm 0.5 \\
10\end{array}$ & $5.17 \pm 0.157$ & $\begin{array}{l}5.17 \pm 0 . \\
380\end{array}$ & $5.12 \pm 0.289$ & $\begin{array}{l}4.48 \pm 0.1 \\
95\end{array}$ & $5.08 \pm 0.555$ & $\begin{array}{l}4.155 \pm 0 . \\
171\end{array}$ & $\begin{array}{l}5.40 \pm 0.216 \\
* *\end{array}$ & $\begin{array}{l}3.91 \pm 0.2 \\
67\end{array}$ & $\begin{array}{l}5.08 \pm 0.220 \\
* *\end{array}$ \\
\hline 12 & $\begin{array}{l}6.56 \pm 0.5 \\
43\end{array}$ & $\begin{array}{l}3.80 \pm 0.407 * \\
*\end{array}$ & $\begin{array}{l}4.04 \pm 0 . \\
391\end{array}$ & $3.57 \pm 0.628$ & $\begin{array}{l}3.82 \pm 0.4 \\
26\end{array}$ & $3.08 \pm 0.275$ & $\begin{array}{l}3.32 \pm 0.1 \\
15\end{array}$ & $3.22 \pm 0.193$ & $\begin{array}{l}2.76 \pm 0.1 \\
61\end{array}$ & $2.89 \pm 0.170$ \\
\hline 24 & $\begin{array}{l}16.37 \pm 3 . \\
21\end{array}$ & $\begin{array}{l}3.64 \pm 0.168 * \\
*\end{array}$ & $\begin{array}{l}13.21 \pm 1 \\
.70\end{array}$ & $\begin{array}{l}3.42 \pm 0.639 * \\
*\end{array}$ & $\begin{array}{l}11.51 \pm 0 . \\
468\end{array}$ & $\begin{array}{l}2.62 \pm 0.193 * \\
* *\end{array}$ & $\begin{array}{l}9.60 \pm 0.7 \\
44\end{array}$ & $\begin{array}{l}3.24 \pm 0.377 \\
* * *\end{array}$ & $\begin{array}{l}6.50 \pm 0.1 \\
999\end{array}$ & $\begin{array}{l}3.73 \pm 0.036 \\
* * *\end{array}$ \\
\hline
\end{tabular}

$*$ Between normal and Pasteurella multocida infected goats. $\mathrm{N}=$ Normal $\mathrm{I}=$ infected $* \mathrm{P}<0.05 * * \mathrm{P}<0.01 * * * \mathrm{P}<0.001$

Table 9: Creatinine Clearance (M1/Min/10kg.B.Wt) of Thiamphenicol in Normal and Experimentally Pasteurella multocida Infected Goats Following Repeated Intramuscular Injection of $30 \mathrm{Mg}$ Thiamphenicol /Kg. B. Wt. Once Daily for Five Consecutive Days (N=4)

\begin{tabular}{|c|c|c|c|c|c|c|c|c|c|c|}
\hline \multirow[t]{2}{*}{$\begin{array}{l}\text { Time of } \\
\text { administra- } \\
\text { tion } \\
\text { (h) }\end{array}$} & \multicolumn{6}{|c|}{$\begin{array}{ll}\text { Dose } & \\
\text { First } & \text { Second_ } \\
-(X \pm S . \text { E. }) & (\mathrm{X} \pm \text { S. E. })\end{array}$} & \multicolumn{2}{|l|}{$\begin{array}{l}\text { Fourth } \\
(\mathrm{X} \pm \text { S. E.) }\end{array}$} & \multicolumn{2}{|l|}{$\begin{array}{l}\text { Fifth_} \\
(\mathrm{X} \pm \text { S. E.) }\end{array}$} \\
\hline & $\mathrm{N}$ & I & $\mathrm{N}$ & I & $\mathrm{N}$ & I & $\mathrm{N}$ & I & $\mathrm{N}$ & I \\
\hline 0.50 & $8.46 \pm 1.22$ & $8.86 \pm 1.18$ & $9.93 \pm 1.59$ & $10.64 \pm 1.81$ & $\begin{array}{l}11.58 \pm 1.3 \\
6\end{array}$ & $\begin{array}{l}13.08 \pm 1.1 \\
9\end{array}$ & $\begin{array}{l}15.37 \pm 1.0 \\
3\end{array}$ & $\begin{array}{l}17.13 \pm 0.8 \\
16\end{array}$ & $\begin{array}{l}17.69 \pm 2.2 \\
1\end{array}$ & $\begin{array}{l}18.21 \pm 2.3 \\
2\end{array}$ \\
\hline 1 & $\begin{array}{l}12.96 \pm 2.6 \\
0\end{array}$ & $\begin{array}{l}19.02 \pm 2.6 \\
4\end{array}$ & $\begin{array}{l}15.88 \pm 5.8 \\
8\end{array}$ & $15.26 \pm 3.44$ & $\begin{array}{l}15.79 \pm 3.7 \\
5\end{array}$ & $\begin{array}{l}19.10 \pm 4.5 \\
9\end{array}$ & $\begin{array}{l}15.79 \pm 3.8 \\
8\end{array}$ & $\begin{array}{l}20.55 \pm 4.6 \\
6\end{array}$ & $\begin{array}{l}19.25 \pm 2.2 \\
6\end{array}$ & $\begin{array}{l}20.02 \pm 1.8 \\
9\end{array}$ \\
\hline 4 & $\begin{array}{l}29.87 \pm 6.2 \\
5\end{array}$ & $\begin{array}{l}28.54 \pm 4.9 \\
7\end{array}$ & $\begin{array}{l}24.07 \pm 5.1 \\
2\end{array}$ & $31.87 \pm 6.10$ & $\begin{array}{l}31.24 \pm 5.3 \\
4\end{array}$ & $37.16 \pm 7.6$ & $\begin{array}{l}26.79 \pm 4.8 \\
0\end{array}$ & $\begin{array}{l}34.89 \pm 4.9 \\
6\end{array}$ & $\begin{array}{l}34.22 \pm 5.1 \\
2\end{array}$ & $\begin{array}{l}36.54 \pm 5.4 \\
5\end{array}$ \\
\hline 6 & $\begin{array}{l}16.34 \pm 4.2 \\
2\end{array}$ & $\begin{array}{l}18.19 \pm 7.4 \\
7\end{array}$ & $\begin{array}{l}19.47 \pm 4.8 \\
8\end{array}$ & $19.85 \pm 5.62$ & $\begin{array}{l}18.79 \pm 5.0 \\
4\end{array}$ & $\begin{array}{l}17.95 \pm 2.8 \\
6\end{array}$ & $\begin{array}{l}19.30 \pm 3.9 \\
3\end{array}$ & $\begin{array}{l}19.56 \pm 4.7 \\
1\end{array}$ & $\begin{array}{l}17.10 \pm 5.2 \\
1\end{array}$ & $\begin{array}{l}20.03 \pm 5.0 \\
7\end{array}$ \\
\hline 8 & $\begin{array}{l}16.79 \pm 2.6 \\
7\end{array}$ & $\begin{array}{l}17.98 \pm 3.2 \\
5\end{array}$ & $\begin{array}{l}15.99 \pm 1.7 \\
8\end{array}$ & $16.18 \pm 0.326$ & $\begin{array}{l}17.22 \pm 1.1 \\
9\end{array}$ & $\begin{array}{l}17.19 \pm 1.0 \\
6\end{array}$ & $\begin{array}{l}17.21 \pm 0.4 \\
35\end{array}$ & $\begin{array}{l}19.30 \pm 1.4 \\
3\end{array}$ & $\begin{array}{l}17.57 \pm 1.4 \\
9\end{array}$ & $\begin{array}{l}18.81 \pm 1.6 \\
8\end{array}$ \\
\hline 12 & $\begin{array}{l}14.34 \pm 0.5 \\
73\end{array}$ & $\begin{array}{l}14.07 \pm 0.5 \\
6\end{array}$ & $\begin{array}{l}13.39 \pm 0.5 \\
25\end{array}$ & $\begin{array}{l}15.38 \pm 0.484 \\
* *\end{array}$ & $\begin{array}{l}14.12 \pm 0.4 \\
00\end{array}$ & $\begin{array}{l}14.77 \pm 0.1 \\
14\end{array}$ & $\begin{array}{l}12.45 \pm 1.5 \\
1\end{array}$ & $\begin{array}{l}15.25 \pm 1.1 \\
2\end{array}$ & $\begin{array}{l}15.54 \pm 0.8 \\
39\end{array}$ & $\begin{array}{l}16.31 \pm 0.8 \\
95\end{array}$ \\
\hline 24 & $\begin{array}{l}12.47 \pm 0.9 \\
97\end{array}$ & $\begin{array}{l}12.36 \pm \\
1.02\end{array}$ & $\begin{array}{l}14.52 \pm 1.0 \\
6\end{array}$ & $14.19 \pm 1.09$ & $\begin{array}{l}12.43 \pm 0.8 \\
30\end{array}$ & $\begin{array}{l}14.28 \pm 1.6 \\
1\end{array}$ & $\begin{array}{l}11.96 \pm 1.0 \\
09\end{array}$ & $\begin{array}{l}14.65 \pm 0.7 \\
29\end{array}$ & $\begin{array}{l}16.26 \pm 1.0 \\
4\end{array}$ & $\begin{array}{l}17.00 \pm 1.6 \\
8\end{array}$ \\
\hline
\end{tabular}

* Between normal and Pasteurella multocida infected goats. $\mathrm{N}=$ Normal $\mathrm{I}=$ infected $* \mathrm{P}<0.05 * * \mathrm{P}<0.01 * * * \mathrm{P}<0.001$ 
Table 10: Thiamphenicol Clearance (Ml/Min/10kg. B. Wt) in Normal and Experimentally Pasteurella multocida Infected Goats Following Repeated Intramuscular Injection of $30 \mathrm{Mg}$ Thiamphenicol $/ \mathrm{Kg}$. B. Wt. Once Daily for Five Consecutive Days $(\mathrm{N}=4)$

\begin{tabular}{|c|c|c|c|c|c|c|c|c|c|c|}
\hline \multirow{2}{*}{$\begin{array}{l}\text { Time of } \\
\text { admin- } \\
\text { istration } \\
\text { (h) }\end{array}$} & \multicolumn{2}{|c|}{$\begin{array}{l}\text { First } \\
-(X \pm S . \text { E. })\end{array}$} & \multicolumn{2}{|l|}{$\begin{array}{l}\text { Second } \\
(\mathrm{X} \pm \text { S. E.) }\end{array}$} & \multicolumn{2}{|l|}{$\begin{array}{l}\text { Third_- } \\
\text { ( } \mathrm{X} \pm \text { S. E.) }\end{array}$} & \multicolumn{2}{|l|}{$\begin{array}{l}\text { Fourth } \\
(\mathrm{X} \pm \text { S. E.) }\end{array}$} & \multicolumn{2}{|l|}{$\begin{array}{l}\text { Fifth_- } \\
(\mathrm{X} \pm \text { S. E.) }\end{array}$} \\
\hline & $\mathrm{N}$ & I & $\mathrm{N}$ & I & $\mathrm{N}$ & I & $\mathrm{N}$ & I & $\mathrm{N}$ & I \\
\hline 0.50 & $\begin{array}{l}1.17 \pm 0 . \\
128\end{array}$ & $1.60 \pm 0.137$ & $\begin{array}{l}1.20 \pm 0.1 \\
25\end{array}$ & $\begin{array}{l}2.04 \pm 0.050 * \\
* *\end{array}$ & $\begin{array}{l}1.27 \pm 0.1 \\
37\end{array}$ & $\begin{array}{l}2.26 \pm 0.166^{*} \\
*\end{array}$ & $\begin{array}{l}1.58 \pm 0.1 \\
63\end{array}$ & $\begin{array}{l}2.56 \pm 0.121 * \\
*\end{array}$ & $\begin{array}{l}1.80 \pm 0.2 \\
17\end{array}$ & $\begin{array}{l}2.94 \pm 0.125 * \\
*\end{array}$ \\
\hline 1 & $\begin{array}{l}1.44 \pm 0 . \\
138\end{array}$ & $\begin{array}{l}2.30 \pm 0.215 \\
*\end{array}$ & $\begin{array}{l}1.55 \pm 0.1 \\
76\end{array}$ & $2.46 \pm 0.225^{*}$ & $\begin{array}{l}1.61 \pm 0.3 \\
04\end{array}$ & $2.67 \pm 0.327$ & $\begin{array}{l}1.65 \pm 0.0 \\
92\end{array}$ & $\begin{array}{l}2.59 \pm 0.215 * \\
*\end{array}$ & $\begin{array}{l}1.93 \pm 0.1 \\
58\end{array}$ & $\begin{array}{l}2.76 \pm 0.140 * \\
*\end{array}$ \\
\hline 2 & $\begin{array}{l}1.91 \pm 0 . \\
122\end{array}$ & $\begin{array}{l}2.455 \pm 0.24 \\
2\end{array}$ & $\begin{array}{l}2.02 \pm 0.1 \\
14\end{array}$ & $2.36 \pm 0.098$ & $\begin{array}{l}1.94 \pm 0.0 \\
97\end{array}$ & $\begin{array}{l}2.38 \pm 0.089 * \\
*\end{array}$ & $\begin{array}{l}2.00 \pm 0.1 \\
63\end{array}$ & $2.40 \pm 0.201$ & $\begin{array}{l}1.99 \pm 0.1 \\
07\end{array}$ & $\begin{array}{l}2.81 \pm 0.148 * \\
*\end{array}$ \\
\hline 4 & $\begin{array}{l}5.21 \pm 0 . \\
346\end{array}$ & $\begin{array}{l}3.41 \pm 0.458 \\
*\end{array}$ & $\begin{array}{l}4.61 \pm 0.3 \\
14\end{array}$ & $\begin{array}{l}3.21 \pm 0.115^{*} \\
*\end{array}$ & $\begin{array}{l}4.07 \pm 0.0 \\
75\end{array}$ & $3.68 \pm 0.214$ & $\begin{array}{l}3.89 \pm 0.2 \\
19\end{array}$ & $3.47 \pm 0.346$ & $\begin{array}{l}4.00 \pm 0.1 \\
63\end{array}$ & $4.09 \pm 0.328$ \\
\hline 6 & $\begin{array}{l}2.27 \pm 0 . \\
144\end{array}$ & $2.24 \pm 0.240$ & $\begin{array}{l}1.86 \pm 0.1 \\
61\end{array}$ & $2.36 \pm 0.152$ & $\begin{array}{l}1.66 \pm 0.0 \\
99\end{array}$ & $2.18 \pm 0.203$ & $\begin{array}{l}1.41 \pm 0.0 \\
55\end{array}$ & $\begin{array}{l}2.08 \pm 0.151 * \\
*\end{array}$ & $\begin{array}{l}1.33 \pm 0.0 \\
70\end{array}$ & $\begin{array}{l}1.99 \pm 0.050 * \\
* *\end{array}$ \\
\hline 8 & $\begin{array}{l}1.31 \pm 0 . \\
134\end{array}$ & $1.19 \pm 0.077$ & $\begin{array}{l}1.11 \pm 0.0 \\
48\end{array}$ & $1.2 \pm 0.033$ & $\begin{array}{l}0.962 \pm 0 \\
088\end{array}$ & $0.952 \pm 0.330$ & $\begin{array}{l}0.906 \pm 0 . \\
048\end{array}$ & $\begin{array}{l}1.36 \pm 0.063 * \\
*\end{array}$ & $\begin{array}{l}0.913 \pm 0 \\
074\end{array}$ & $\begin{array}{l}1.34 \pm 0.016^{*} \\
*\end{array}$ \\
\hline 12 & $\begin{array}{l}1.09 \pm 0 . \\
090\end{array}$ & $\begin{array}{l}0.688 \pm 0.09 \\
5^{*}\end{array}$ & $\begin{array}{l}0.697 \pm 0 \\
081\end{array}$ & $0.561 \pm 0.075$ & $\begin{array}{l}0.665 \pm 0 . \\
078\end{array}$ & $0.687 \pm 0.105$ & $\begin{array}{l}0.681 \pm 0 . \\
069\end{array}$ & $0.626 \pm 0.019$ & $\begin{array}{l}0.547 \pm 0 \\
028\end{array}$ & $0.651 \pm 0.052$ \\
\hline 24 & $\begin{array}{l}2.50 \pm 0 . \\
621\end{array}$ & $\begin{array}{l}0.149 \pm 0.00 \\
5 * *\end{array}$ & $\begin{array}{l}2.14 \pm 0.3 \\
02\end{array}$ & $\begin{array}{l}0.172 \pm 0.009 \\
* * *\end{array}$ & $\begin{array}{l}1.80 \pm 0.0 \\
94\end{array}$ & $\begin{array}{l}0.152 \pm 0.014 \\
* * *\end{array}$ & $\begin{array}{l}1.54 \pm 0.1 \\
50\end{array}$ & $\begin{array}{l}0.178 \pm 0.003 \\
* * *\end{array}$ & $\begin{array}{l}1.29 \pm 0.0 \\
64\end{array}$ & $\begin{array}{l}0.214 \pm 0.013 \\
* * *\end{array}$ \\
\hline
\end{tabular}

* Between normal and Pasteurella multocida infected goats. $\mathrm{N}=$ Normal $\mathrm{I}=$ infected $* \mathrm{P}<0.05 * * \mathrm{P}<0.01 * * * \mathrm{P}<0.001$

Table 11: Thiamphenicol Clearance /Creatinine Clearance in Normal and Experimentally Pasteurella multocida Infected Goats Following Repeated Intramuscular Injection of $30 \mathrm{Mg}$ Thiamphenicol $/ \mathrm{Kg}$. B. Wt. Once Daily for Five Consecutive Days (N=4)

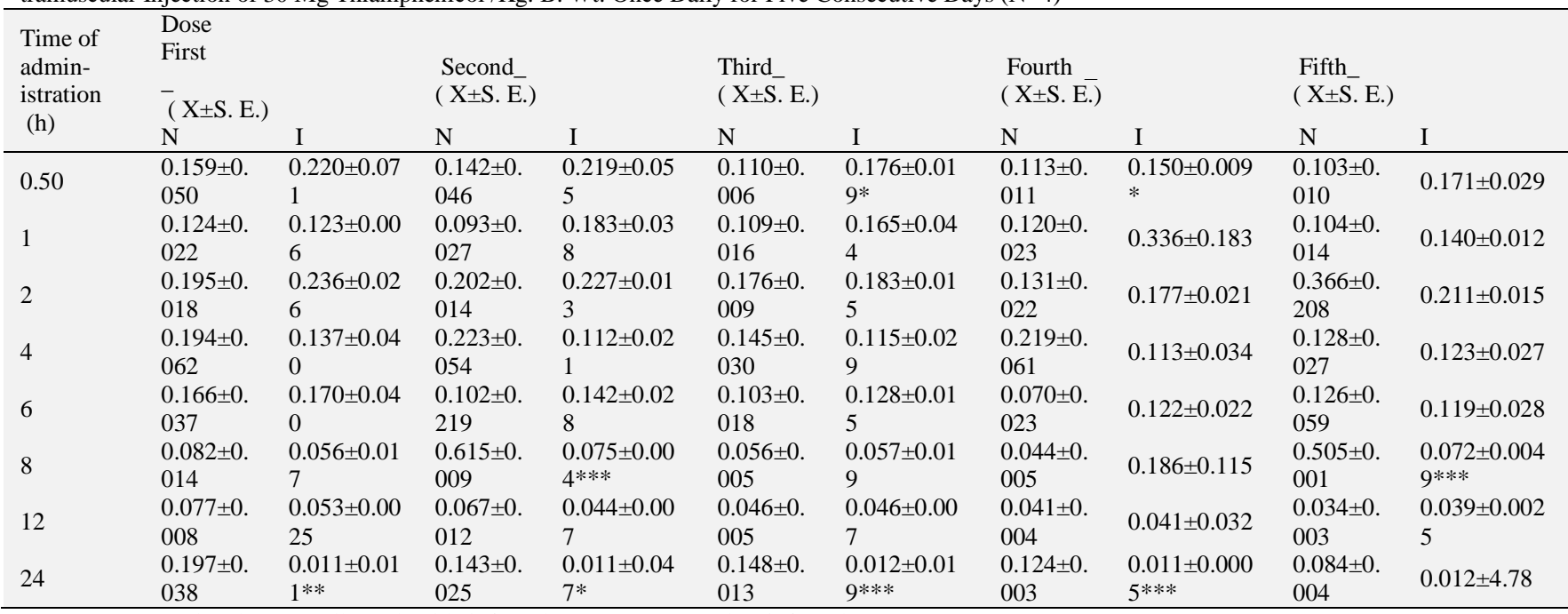

$*$ Between normal and Pasteurella multocida infected goats. $\mathrm{N}=$ Normal $\mathrm{I}=$ infected $* \mathrm{P}<0.05 * * \mathrm{P}<0.01 * * * \mathrm{P}<0.001$

\section{Discussion}

Following a single intravenous injection of $30 \mathrm{mg}$ thiamphenicol/kg.b.wt. in normal goats, the drug showed high serum level $(90 \pm 0.707 \mu \mathrm{g} / \mathrm{ml})$ at 5 minutes post-injection, then its concentration was decreased gradually till reached its minimum level $(0.645 \pm 0.033 \mu \mathrm{g} / \mathrm{ml})$ at 24 hours post-injection.

In the present investigation, the intravenous injection of $30 \mathrm{mg}$ thiamphenicol / kg.b.wt. In normal goats, showed that the drug disposition best fitted a two-compartments- open model, a compartment of plasma and rapid equilibrating tissues, and a deeper slower compartment. The obtained result is consistent with those reported for thiamphenicol in pre-rumminant labs and calves(Mengozzi et al .2002), male goats (Bogazil and Tohamy 2015). Also this phenomenon is in agreement with those reported for other amphenicols as choloramphenicol in calves (Watson and Black 1986), florfenicol in pigs (Jianzhong et al. 2003), healthy foal ( Tohamy and Radi 2008). On contrast this result isn't agreed with that reported for florfenicol in healthy sheep, Jianzhong et al. 2004), cattle (Lobell et al 2008) as reported by three compartment. Thiamphenicol was distributed after intravenous injection with a distribution phase $(\alpha)$ equal to 8.25 per hour with a short distribution half - life $\left[\mathrm{t}_{0.5(\alpha)}\right]$ equal to 0.084 hour. The shorter distribution half-life of thiamphenicol in goats suggested the rapid distribution of the drug in body tissue and fluid and that nearly similar to that recorded for cholramphenicol in healthy skotored goats ( $0.08 \mathrm{~h}$ ) (Etuk et al. 2005) , and nearly similar to that reported for thiamphenicol in neagle blog $(0.069 \mathrm{~h})$ (Yang et al 2011), in male goats $(0.06 \mathrm{~h})$ (Bogazil and Tohamy 2015). On the other hand, this result is slightly shorter than that reported for thiamphenicol in sheep, camel (0.151h) and (0.165h) (Al Nazawi 2005) ,florfenicol in healthy foal $(0.194 \mathrm{~h})$ (Tahamy and Radi 2008)

The rapid distribution of thiamphenicol in goats is supported by high rate constant of transfer of the drug from central to peripheral compartment $\left[\mathrm{K}_{12}=5.75 \mathrm{~h}^{-1}\right]$ as compared to the rate constant of transfer of the drug from peripheral to central compartment $\left[\mathrm{K}_{21}=2.06 \mathrm{~h}^{-1}\right]$. This value is higher than those recorded for thiamphenicol in lambs and calves $\left(\mathrm{K}_{12}=0.80,0.29 \mathrm{~h}^{-1}\right.$ and $\mathrm{K}_{21}=$ $0.54,0.23 \mathrm{~h}^{-1}$ ) (Mengozzi et al. 2002), for florfenicol in broiler chicken $\left(\mathrm{K}_{12}=2.5 \mathrm{~h}^{-1}\right.$ and $\left.\mathrm{K}_{21}=0.85 \mathrm{~h}^{-1}\right)(\mathrm{El}$ Banna and El Zorba 2011).

The apparent volume of distribution of thiamphenicol at steedy state (Vdss ) is an accurate indication for the diffusion of the drug into the body tissue ( Gilman et al 1980). Thiamphenicol showed Vdss of $0.785 \mathrm{~L} / \mathrm{Kg}$, this value is nearly similar to those recorded for thiamphenicol in sheep $(0.68 \mathrm{~L} / \mathrm{kg})$ (Al Nazawi 2005) and in male goats ( $0.51 \mathrm{~L} / \mathrm{kg}$ ) (Bogazil and Tohamy 2015). Thiamphenicol showed smaller Vdss in comparison to those in lactating cattle (1.22 L/kg) (Mestorino et al 1993), dairy cattle ( $0.9 \mathrm{l} / \mathrm{kg}$ ) (Abdennabi et al 1994 b) ,camel (0.97 L/kg) (Al Nazawi 2005) .On the other hand, thiamphenicol in lactating goats in this study 
showed larger Vdss compared to those reported in beagle dogs $(0.264 \mathrm{~L} / \mathrm{kg}$ ) (Yang et al 2011).

High value of the volume of distribution suggested extensive penetration power. Drug with volume of distribution greater than one liter/kilogram indicated wide distribution or extensive tissue binding or both (Baggot, 1977). The apparent volume of distribution in the present study indicated moderate tissue penetrating power.

Thiamphenicol is eliminated in the current study following a single intravenous injection with elimination half -life $\left[\mathrm{t}_{0.5(\beta)}\right]$ equal to $4.15 \mathrm{~h}$. This observation is nearly agreed with the data recorded for choloramphaenicol in sheep $(3.24 \mathrm{~h}$ ) (Mestorino and Errecalde 1998), thiamphenicol in calves and lambs (3.50 and $3.76 \mathrm{~h}$ ) (Mengozzi et al 2002) .On contrast, this value was longer than those reported for thiamphenicol in pigs $(1.2 \mathrm{~h})$ (Castells et al 2001),sheep (1.2 h) (Al Nazawi 2005), dog (1.17h ) (Yang et al 2011) and male goats(1.2h) (Bogazil and Tohamy 2015) ,On contrast, this value is shorter than those recorded for florfenicol in sheep $(18.83 \mathrm{~h})$ (Jianzhong et al 2004) and healthy foal $(7.20 \mathrm{~h})$ (Tohamy and Radi 2008).

The rate of total body clearance of thiamphenicol following a single intravenous injection is $0.002 \mathrm{~L} / \mathrm{kg} / \mathrm{h}$, this value is lower than that reported for thiamphecicol in lambs and calves $(0.40$ and $0.58 \mathrm{~L} / \mathrm{kg} / \mathrm{h})($ Mengazzi et al 2002), in male goats $(0.51 \mathrm{~L} / \mathrm{kg} / \mathrm{h})$ (Bogazil and Tohamy 2015) . Also it lower than those reported for other amphenicols as that reported for florfenicol in egyptian goats $(3.306 \mathrm{~L} / \mathrm{kg} / \mathrm{h})($ Atef et al 2000), in camel ,sheep and goats( 0.33 , 0.30 and $0.27 \mathrm{~L} / \mathrm{kg} / \mathrm{h}$ ) (Ali et al 2003), in rabbit $(0.34 \mathrm{~L} / \mathrm{kg} / \mathrm{h}$ ) (Abd El Aty et al 2004) in healthy sheep $(0.26 \mathrm{~L} / \mathrm{kg} / \mathrm{h})($ Jianzhong et al 2004), in pigs $(0.23 \mathrm{~L} / \mathrm{kg} / \mathrm{h})$ (Jianghong et al 2006) and in healthy brioler chicken $(0.38 \mathrm{~L} / \mathrm{kg} / \mathrm{h})$ (El Banna and EL Zorba 2011)

The variation in total body clearance might be attributed to specific interspecies variation, handling of the drug, method used, healthy status of the animals (Baggot, 1980).

The difference between values calculated for pharmacokinetic parameters may be attributed to animal species, the drug formulation employed, the age, the size or sex of the animal or even inter individual variation and also due to method of analysis of the drug (Hadded et al.1985).

Following a single intramuscular injection of $30 \mathrm{mg}$ thiampheni$\mathrm{col} / \mathrm{kg}$ bwt. In normal goats, the drug reached its peak serum concentrations after two hour of injection with a value of $(20 \mu \mathrm{g} / \mathrm{ml})$. Thiamphenicol could be detected in serum in a therapeutic level $(0.357 \mu \mathrm{g} / \mathrm{ml})$ at 24 hours post-injection. The reported peak serum concentrations neerly similar to those reported for thiamphenicol in sheep $(19.50 \mu \mathrm{g} / \mathrm{ml})$ (Abdennabi and Stowe 1994), camel (18.5 $\mu \mathrm{g} / \mathrm{ml}$ ) (Al Nazawi 2005).On contrast this result is higher than that recorded for chloamphenicol in sheep $(15.75 \mu \mathrm{g} / \mathrm{ml})$ (Mestorino and Errecalde 1998)). Otherwise, it is lower than that reported for thiamphenicol in lactating cattle $(30.90 \mu \mathrm{g} / \mathrm{ml})$ ( Mestorino et al 1993).

The calculated maximum serum concentration $\left(\mathrm{C}_{\max }\right)$ is $(16.67 \mu \mathrm{g} / \mathrm{ml})$ at maximum time $\left(\mathrm{t}_{\max }\right)$ is equal to 1.42 of hours. The reported maximum serum concentration $\left(\mathrm{C}_{\max }\right)$ is higher than those reported for thiamphenicol in lambs and calves (5.20 and $3.51 \mu \mathrm{g} / \mathrm{ml}$ ) (Mengozzi et al 2002), in male goats $(6.89 \mu \mathrm{g} / \mathrm{ml})$ (Bogazil and Tohamy 2015). Also it is higher than those reported for other amphenicls as that reported for florfenicol in pigs (4 $\mu \mathrm{g} / \mathrm{ml}$ ) (Jianzhong et al 2003), healthy foal $(4.709 \mu \mathrm{g} / \mathrm{ml})$ (Tohamy and Radi 2008), in goats (3.07 $\mu \mathrm{g} / \mathrm{ml})$ (Verma et al 2009), in broiler chicken $(6.8 \mu \mathrm{g} / \mathrm{ml})$ (El Banna and El Zorba 2011) and in dogs $(3.05 \mu \mathrm{g} / \mathrm{ml})$ (Birdane and Birdane 2015) . On the other hand, the result was lower than that reported by Abd El Aty et al (2004) who detected the maximum serum concentration $\left(C_{\max }\right)$ of florfenicol in rabbits after intramuscular administration with a value of $(21.65 \mu \mathrm{g} / \mathrm{ml})$.

The reported $\left[t_{\max }\right]$ is neerly similar to that reported for florfenicol in pigs $(1.00 \mathrm{~h})$ (Jianzhong et al 2006) $_{\text {.On contrast, it is longer }}$ than those reported for thiamphenicol in sheep $(0.37 \mathrm{~h})$ ( $\mathrm{Ab}$ dennebi and Stowe 1994) and for choloramphenicol in sheep( $10.00 \mathrm{~min}$ ) (Wesongah et al 2009) .
The elimination half life $\left[\mathrm{t}_{0.5(\beta)}\right]$ following a single intramuscular administration was 4.02 hours. This value is nearly similer to that recorded for florfenicol in pigs (3.91 hours) (Jianzhong et al 2003) ,On contrast, this result is longer than that reported for thiamphenicol in sheep (1.51 hours) (Abdennebi and Stowe 1994). One the other hand, this result is shorter than those reported for chloramphenicol in sheep (5.75 hours) (Mestorino and Errecalde 1998), for florfenicol in sheep (18.71 hours) (Jianzhong et al 2004), and in pigs( 17.2hours ) (Jianzhong et al 2006).

The rate of total body clearance of thiamphenicol following a single intramuscular injection is $0.0016 \mathrm{~L} / \mathrm{kg} / \mathrm{h}$. This value was lower than that reported for chloramphenicol in cattle,$(0.128 \mathrm{~L}$ $/ \mathrm{kg} / \mathrm{h}$

) ( Sanders et al 1988). For florfenicol in sheep $(0.25 \mathrm{~L} / \mathrm{kg} / \mathrm{h})$ (Jianzhong et al 2004)

Bioavailability is the fraction of the drug administered by non vascular rout that gains accesses to the systemic circulation. The obtained result revealed that the calculated systemic bioavailability percent was $66.63 \%$. It is nearly equal to those recorded for chloramphenicol in sheep (65\%, Mestorino and Errecalde 1998), florfenicol in egyptian goats $(65.71 \%)$ (Atef et al 2000), and for florfenicol in sheep (65.82\%) (Ali et al 2003). On contrast, it is higher than those recorded for thiamphenicol in rabbit $(16.2 \%)$ (Aldana et al 1992), preruminant calf 62\%) (Intorre et al 1997), lambs and calves (60\%) for both species, (Mengozzi et al 2002), and for florfenicol in dogs ( 44.70\%) (Birdane and Birdane 2015). Also it is higher than that reported for other amphenicols as those reported for chloramphenicol in cattle $(19.1 \%)$ (Sanders et al 1988 ) and for florfenicol in diseased broiler chicken (55\%) (El Banna and El Zorba 2011). On the other hand, this value is lower than those reported for thiamphenicol in beef and dairy cattle( 84 $\%$ ) (Abdennabi et al 1994 b), male goats $(87.61 \%$ ) ( Bogazil and Tohamy 2015) ,and also lower than those reported for other amphenicols as that reported for florfenicol in rabbit $(88.25 \%)$ ( Abd El Aty et al 2004), pigs (96.9\%)( Jianghong et al 2006), in healthy foal $(73.48 \%$ ) (Tohamy and Radi 2008$)$, goats $(87.64 \%)$ (Verma et al 2009), broiler chicken (71.5\% ) (El Banna and El Zorba 2011), and for chloramphenicol in Sokoto red goats( $80 \%)$ (Etuk et al 2005).

Repeated intramusculer adminsteration of thiamphenicol in normal and Pasteurella multocida infected goats once dialy for 5 consecutive days revealed that the drug could be could be detected in a therapeutic level for 24 hours following repeated intramuscular administrations and exceeded the minimum inhibitory concentration $\left(\mathrm{MIC}_{90}\right)$ of thiamphenicol $(0.3 \mu \mathrm{g} / \mathrm{ml}$ ).

The relative higher serum concentrations of thiamphenicol after the last dose compared to the first doses indicated the accumulation of thiamphenicol in blood during multiple dosing at 24 hours intervals for five consecutive days. These observations agreed with data reported by Lohani et al (2010), who found that increase in the mean plasma concentration of following the oral adminsteration of florfenicol in chicken given a dialy dose of 30 $\mathrm{mg} / \mathrm{kg} \mathrm{b.wt} \mathrm{for} \mathrm{five} \mathrm{consecutive} \mathrm{days.The} \mathrm{study} \mathrm{showed} \mathrm{that} \mathrm{the}$ blood concentrations of thiamphenicol in Pasteurella multocida infected goats are significantly lower than those in normal goats following repeated intramuscular injection. These lower blood concentrations in Pasteurella multocida infected goats might be attributed to the higher penetrating power of thiamphenicol to the diseased tissues (Baggot, 1980). This phenomenon is similar to data recorded by El banna and El Zorba (2011), who found that the maximum plasma concentration of florfenicol detected in control healthy broiler chicken was higher than that detected in infected bird . On contrast this result is differ than that recorded by Perez et al (2015)who showed that intravenous administration of E.coli lipopolysaccharide in sheep produce higher plasma concentrations of florfenicol due to decrease in the total body clearance of the drug .

In this study, the total body clearance ( $\left.\mathrm{CL}_{\text {tot }}\right)$ in normal goats are lower than in Pasteurella multocida infected goats. This result supported by Abdulgafar et al. (2011) and Etuk and Onyeyili, (2006), fever and inflammation are cardinal features in bacterial 
infection, which may in turn caused an increase in heart rate and cardiac output, increasing blood flow to the liver and kidneys, all these could lead to increased in the rate at which the drug was delivered to both organs which were important sites of drug excretion. This might somewhat explain the increase in the total body clearance in infected goats. This result is differ than that reported by (Perez et al 2015) who observed that the clearance of florfenicol was significantly reduced in Ecoli infected sheep than in non infected animals.

The highest concentrations of thiamphenicol in milk are recorded 4 hours after each intramuscular injection with significant lower values in Pasteurella multocida infected goats than in normal goats. This might be attributed to accumulation of drug in the inflammed tissues (Baggot, 1980). This result is similar to those reported by El-sayed et al, (1989) and (1994) who found that milk concentrations of gentamicin and cephradine were significantly lower in infected goats and cattle than in normal ones, respectively.

From the obtained results, the dose of thiamphenicol used in the present study induced therapeutically concentrations in milk. These concentrations suggested that, thiamphenicol would be efficacious in treatment of mastitis caused by sensitive organisms in lactating goats at dose $30 \mathrm{mg} / \mathrm{kg}$ bwt. daily for 3-5 days.

The mean peak urine concentrations of thiamphenicol were reached 4 hours after each intramuscular injection. The lower urine thiamphenicol concentrations in pasteurella multocida infected goats than in normal goats might be attributed to the accumulation of the drug in the inflamed tissues (Baggot, 1980).

The ratio between thiamphenicol clearance and creatinine clearance revealed a significant lower ratio in pasteurella multocida infected goats than in normal goats at different time of sampling. This indicates that glomerular filteration seemed to be the main pathway of thiamphenicol elimination. This observation supported by (El-Sayed et al 1994) who found that, the ratio between cephradine clearance from blood of goats to creatinine clearance showed a marked decrease in Escherichia-coli infected goats than in normal goats. This indicated that glomerular filteration seemed to be the main pathway of cephradine elimination with a limited rate of tubular reabsorption

\section{Conclusion}

The intramuscular bioavailability of thiamphenicol in normal goats was $66.63 \%$. This value referred a better absorption of thiamphenicol from its site of intramuscular administration. The high milk concentrations of thiamphenicol e in lactating goats after repeated intramuscular administrations, suggested that thiamphenicol could be used for treatment of infection caused by sensitive microorganisms to thiamphenicol in lactating goats. The high concentrations of thiamphenicol in urine after repeated intramuscular administrations, suggested that thiamphenicol is a suitable antimicrobial for treatment of urinary tract infections caused by microorganisms sensitive to thiamphenicol in goats.

\section{References}

[1] Abd-El-Aty. A.M.; Goudah, A.; Abo, E. S. K; El Zorba H.Y;Shimoda .M and Zhou H.H ( 2004): Pharmacokinetics and bioavailability of florfenicol following intravenous, intramuscular, and oral adminsteration in rabbit. Vet Res Commun. 28: 515-524. https://doi.org/10.1023/B:VERC.0000040241.06642.49.

[2] Abdennebi E.H; Sawchuk RJ and Stowe C.M.(1994 b): Thiamphenicol pharmacokinetics in beef and dairy cattle. J Vet Pharmacol Ther. 17(5):365-368. https://doi.org/10.1111/j.13652885.1994.tb00260.x.

[3] Abdennebi.E.H, Stowe.C.M (1994): Pharmacokinetics and distribution of thiamphenicol in sheep given repeated intramuscular doses. Vet. Res. 25,489-494.

[4] Abdulgafar. O;Jimoh; Shaibu.o . B; Emmanuel U. E; SolomonA.A and Vincent U. I. (2011): Comparative Pharmacokinetics of intramuscular ceftriaxone Co- administered with acetaminophen in healthy and infected sokoto Red goats. Inter. J. Pharmacol 7 (5): 623-628

[5] Aldana.I, Fos .D, Gonzalez B, Gazzaniga A, CeppiM, Figini PG, Zato.MA, Bruseghini.L, and Esteras A.( 1992): Oculer pharmacokinetics of thiamphenicol in rabbit Arzenimittelforschung 42 (10) 1236-1239.

[6] Ali B.H; Al-Qarawi A.A and Hashaad M. (2003): Comparative plasma pharmacokinetics and tolerance of florfenicol following intramuscular and intravenous administration to camels, sheep and goats Vet Res Commun. 27(6):475-483. https://doi.org/10.1023/A:1025741724701.

[7] Al-Nazawi, M.H. (2005): Pharmacokinetics and tolerance of thiamphenicol in camels and sheep. Inter.J. Pharmacol. 1 (1) 25-28. https://doi.org/10.3923/ijp.2005.25.28.

[8] Arret,B;Hohnson,D.P and kirshbaum,A(1971) : Outline of details for microbiological assay of antibiotics : second revision $\mathrm{J}$. $\begin{array}{lllll}\text { Pharm } & \text { Sci. } & 60 & \text { (11) }\end{array}$ https://doi.org/10.1002/jps.2600601122.

[9] Atef .M; El-Gendi A.Y; Aziza M.M and Abd El-Aty A.M (2000): Pharmacokinetic properties of florfenicol in Egyptian goats. Dtsch Tierarztl Wochenschr. Apr;107(4):147-150.

[10] Baggot, J.D. (1977): Priniciple of pharmacokinetics .In principle of drug disposition in domestic animals. The physiological Basis of veterinary Clinical Pharmacology, 1st ed.WB Saunders Co. Philadelphi, PA. 168-179.

[11] Baggot, J.D (1978a) some aspect of clinical pharmacokinetics in veterinary medicine I J.Vet.Pharm.Ther. 1: 5-18 https://doi.org/10.1111/j.1365-2885.1978.tb00300.x.

[12] Baggot, J.D (1978b) some aspect of clinical pharmacokinetics in veterinary medicine II. J.Vet.Pharm.Ther. 1: 111-118. https://doi.org/10.1111/j.1365-2885.1978.tb00314.x.

[13] Baggot .J.D. (1980): Distribution of antimicrobial agents in normal and diseased animals. J.A.V.M.A. 19 (76): 1085-1090.

[14] Bennett .J.V; Brodie, J.L; Benner, E and Kibry, W (1966): Simplified accurate method for antibiotic assay for clinical specimen. Appl. Microbial 14: 170-175.

[15] Bogzil,A.H and Tohamy, M.A (2015) Pharmacokinetics and bioavailability of Thiamphenicol glycinate $\mathrm{HCl}$ in male goats. IJDDHR 5(1):849-854.

[16] Birdane Y.o and Birdane F.M (2015): Pharmacokinetics of florfenicol following intravenous and intramuscular adminsteration in dogs. Veterinaria Medicina 60(6): 323-329. https://doi.org/10.17221/8247-VETMED.

[17] Castells G, Capece .B, Pérez B, Martì G, Arboix M, Cristòfol C. (2001): Allometric analysis of thiamphenicol disposition among seven mammalian species J Vet Pharmacol Ther. 24(3) 193-197. https://doi.org/10.1046/j.1365-2885.2001.00331.x.

[18] El-Banna H.A and El-Zorba H.Y (2011) Pharmacokinetics of florfenicol (Water soluble formulation) in healthy and Pasteurella infected broiler chickens. World Rural Observ 3(1):13-19.

[19] El-Sayed, M.G.; Atef, M. and El-Komy, A.A. (1994): Disposition kinetic of cephradine in normal and Escherichia coli infected goats. Dtsch.Tierarztl. Wochenschr. 101(2): 56-60.

[20] El-Sayed. M.G.; Hatem. M.E. and El-Komy, A.A. (1989): Disposition kinetic of gentamicin in normal and endometric cow using microbiological assay. Dtsch.Tierarztl. Wochenschr. 96(8): 412-415.

[21] Etuk. E.U and Onyeyili P.A. (2006): The effect of Salmonella infection on the plasma kinetic of chloramphenicol in the sokoto red goats. Inter. J. Pharmacol. 2(1): 28-32. https://doi.org/10.3923/ijp.2006.28.32.

[22] Gilman, A.G.; Goodman. L.S. and Ghman, A, (1980): Goodman and Gilman's: The pharmacological basis of therapeutics, 6th ed. (New York, MacMillian), pp. 21.

[23] Grove .D.C and Randall W.A (1955): Assay methods of antibiotics. Medical encyclopedia ,New York 79 (12) 259-32

[24] Haddad, N. S.; Pedersoli, W. M.; Ravis, W. R.; Fazeli, M. H. and Carson Jr, R. L. (1985): Pharmacokinetics of gentamicin at steadystate in ponies: serum, urine, and endometrial concentrations. Am. J. Vet. Res. 46(6): 1268-1271.

[25] Intorre L;Mengozzi,.G; Bertini. S; Fabbrini. M;Soldani. G and Secchiari. P (1997): Pharmacokinetics of thiamphenicol in the preruminant calf. Atti della Societa vol 51:249-250.

[26] Jianzhong.S; Fung .K.F; Chen .Z; Zeng. Z and Zhang .J (2003): Pharmacokinetics of florfenicol in healthy pigs and in pigs experimentally infected with Actinobaccilus pleuropneumoniae. Antimicrob. Ag .chemother. 47(2) 820-823.

[27] Jianzhong.S; Xiubo.L; Haiyang.J and Walter.H.H (2004): Bioavailability and pharmacokinetics of florfenicol in healthy sheep. J Vet Pharmacol Ther 27(3): 163-168. https://doi.org/10.1111/j.13652885.2004.00574.x. 
[28] Jianzhong.S, Zeng. Z, Chen .Z, Liu JJ, and Fung .K.F (2006): Pharmacokinetics of florfenicol in pigs following intravenous, intramuscular or oral adminsteration and the effects of feed intake on oral dosing $\mathrm{J}$.Vet. Pharmacol Ther 29,153-156. https://doi.org/10.1111/j.1365-2885.2006.00727.x.

[29] Li. S,Maxwell, R.J. and Shadwell, RJ,( 2002): Solubility of amphenicol bacteriostats in CO2. Fluid Phase Equilibria 198:67-80. https://doi.org/10.1016/S0378-3812(01)00745-2.

[30] Lohani M; Ahmad A.H; Singh K.p and Sheetal V (2010): Pharmacokinetics and residual studies of florfenicol following multiple dose oral administration in Poultry. J. Appl. Anim. Res. 38: 9-12. https://doi.org/10.1080/09712119.2010.9707145.

[31] Lobell R.D; Varma K.J; Johnson J.C; Sams R.A; Gerken D.F and Ashcraft S.M (1994): Pharmacokinetics of florfenicol following intravenous and intramuscular doses to cattle. J. Vet. Pharmacol. Ther. Aug; 17 (4): 253-258.

[32] Mengozzi G; Intorre L; Bertini S; Giorgi M; Secchiari PL and Soldani G (2002): A comparative kinetic study of thiamphenicol in pre-ruminant lambs and calves. Res Vet Sci. 2002 Dec;73(3):291295. https://doi.org/10.1016/s0034-5288(02)00110-8.

[33] Mestorino .N; Landoni M.F; Alt M and Errecalde J.O (1993): The pharmacokinetics of thiamphenicol in lactating cows. Vet Res Commun 17(4):295-303. https://doi.org/10.1007/BF01839220.

[34] Mestorino O.N, Errecalde J.O. (1998): Chloramphenicol pharmacokinetics after intravenous and intramuscular administration in sheep Zentralbl Veterinarmed A;45(3):175-180. https://doi.org/10.1111/j.1439-0442.1998.tb00814.x.

[35] Murray. R (1984): Creatinin .kaplane etal .Clinc Chem Ther .C.V Mosby Co .S Louis. Toronto. Princeton 1261-1266 and 418. Zentralbl Veterinarmed A;45(3):175-180.

[36] Perez R; Palma C; Drapela C; Espinosa. A and Penaillo A.K (2015): Pharmacokinetics of florfenicol after intravenous admnisteration in Escherichia coli lipopolysaccharide induces endotoxaemic sheep. J Vet Pharmacol Ther.38 (2) 144-149. https://doi.org/10.1111/jvp.12160.

[37] Sanders P;Guillot P and Mourot D ( 1988): Pharmacokinetics of a long-acting chloramphenicol formulation administered by intramuscular and subcutaneous routes in cattle. J Vet Pharmacol Ther Jun; 11 (2):183-190.

[38] Snedecor, G.W and Cokran, W.G (1980): Statistical method 7th Ed The Iowa state university press, Ames, Iowa, USA 39-63.

[39] Tohamy M.A and Radi A.M (2008): Bioavailability and pharmacokinetics of florfenicol in healthy foals J. Egypt. Soc. Pharmacol. Exp. Ther 29(.2) 529-537.

[40] Turton, J.A., Havard, A.C., Robinson, S.; Holt, D.E.; Andrews, C.M.; Fagg, R. and Williams, T.C, 2000: Anassessment of chloramphenicol and thiamphenicol in the induction of aplastic anaemia in the BALB/c mouse. Food Chem Toxicol 38:925-938. https://doi.org/10.1016/S0278-6915(00)00087-9.

[41] Turton, J.A.; Andrews, C.M.; Havard, A.C.; Robinson, S.; York M.; Williams, T.C. and Gibson, F.M, (2002): Haemotoxicity of thiamphenicol in the BALB/c mouse and Wistar Hanover rat. Food Chem Toxicol 40:1849-1861. https://doi.org/10.1016/S02786915(02)00178-3.

[42] Tullio, V.; Cuffini, A.; Mandras, N.; Roana, J.; Banche, G.;Ungheri, D. and Carlone N (2004) : Influence of thiamphenicol on the primary functions of human polymorphonuclear leucocytes against Streptococcus pyogenes. Int $\mathrm{J}$ Antimicrob Agents 24:381-385. https://doi.org/10.1016/j.ijantimicag.2004.03.027.

[43] Verma, S;Ahmad, A.H; Rahal, Aand Singh, K.P (2009): Pharmacokinetics of florfenicol following single dose intravenous and intramuscular administration in goats. Appl. Anim. Res., 36: 93-96. https://doi.org/10.1080/09712119.2009.9707039.

[44] Wesongah.J.O; Murilla.G.O; Guantai.A.N and Mdachi.R.E (2009) Pharmacokinetics of Chloramphenicol in Sheep after intramuscular adminsteration. East and Central African Journal of Pharmaceutical Sciences Vol. $12: 3-7$

[45] Yang B; Yang L;Jianheng Z;Jing Z;Jiake H; Di Zhao; Pengfei S, andXijing $C$ (2011): Pharmacokinetics of the prodrug thiamphenicol glycinate and its active parent compound thiamphenicol in beagle dogs following intravenous administration. Xenobiotica, 2011 41(3): 226-231. https://doi.org/10.3109/00498254.2010.535218

[46] Zamir .S.M, and Shafarin .M.S. (2007): Response of goats to the different routes of infection by Pasteurella multocida B: 2. J. Animal .vet. Advance. 6(3):340-343. 